\title{
A Core Gene Set Describes the Molecular Basis of Mutualism and Antagonism in Epichloë spp.
}

\author{
Carla J. Eaton, ${ }^{1}$ Pierre-Yves Dupont, ${ }^{1}$ Peter Solomon, ${ }^{2}$ William Clayton, ${ }^{1}$ Barry Scott, ${ }^{1}$ and Murray P. Cox ${ }^{1}$ \\ ${ }^{1}$ Institute of Fundamental Sciences and the Bio-Protection Research Centre, Massey University, Palmerston North, 4442, \\ New Zealand; ${ }^{2}$ Research School of Biology, College of Medicine, Biology and Environment, The Australian National University, \\ Canberra, ACT 0200, Australia
}

Submitted 29 September 2014. Accepted 2 December 2014.

\begin{abstract}
Beneficial plant-fungal interactions play an important role in the ability of plants to survive changing environmental conditions. In contrast, phytopathogenic fungi fall at the opposite end of the symbiotic spectrum, causing reduced host growth or even death. In order to exploit beneficial interactions and prevent pathogenic ones, it is essential to understand the molecular differences underlying these alternative states. The association between the endophyte Epichlö̈ festucae and Lolium perenne (perennial ryegrass) is an excellent system for studying these molecular patterns due to the existence of several fungal mutants that have an antagonistic rather than a mutualistic interaction with the host plant. By comparing gene expression in a wild-type beneficial association with three mutant antagonistic associations disrupted in key signaling genes, we identified a core set of 182 genes that show common differential expression patterns between these two states. These gene expression changes are indicative of a nutrient-starvation response, as supported by the upregulation of genes encoding degradative enzymes, transporters, and primary metabolism, and downregulation of genes encoding putative small-secreted proteins and secondary metabolism. These results suggest that disruption of a mutualistic symbiotic interaction may lead to an elevated uptake and degradation of host-derived nutrients and cell-wall components, reminiscent of phytopathogenic interactions.
\end{abstract}

To gain a competitive advantage, many plants have evolved the ability to form associations or symbioses with microbes, which often enhances their fitness. Fungi, in particular, interact with a wide range of plant species, including the well-characterized interactions between plants and mycorrhizal fungi, which enhance host water and nutrient uptake (Parniske 2008), and the interactions between Epichlö̈ spp. and cool-season grasses, which provide increased protection from herbivory and drought (Schardl 2001). These associations are generally described as mutualistic, because both partners receive a net benefit from the association. However, the overall costs and benefits of these associations vary in time and space dependent

Corresponding author: M. P. Cox; Telephone: (+64) 6 356-9099 x84747; E-mail: m.p.cox@massey.ac.nz

* The $\boldsymbol{e}$-Xtra logo stands for "electronic extra" and indicates that eleven supplementary datasets, three supplementary tables, one supplementary figure, and supplementary methods are published online.

(C) 2015 The American Phytopathological Society on both biotic and abiotic factors (Bronstein 1994; Egger and Hibbett 2004), implying that mutualistic interactions actually fluctuate along a continuum from truly mutualistic to more antagonistic (Bronstein 1994). Understanding the molecular mechanisms that define these alternative states will be crucial to finding mechanisms for both enhancing beneficial interactions and controlling plant disease. The model association formed between the fungal endophyte Epichlö festucae and Lolium perenne (perennial ryegrass) provides an excellent system for investigating these molecular mechanisms because a number of gene deletion mutants exists that exhibit an antagonistic interaction with the host plant. The first such mutant identified was disrupted in the noxA gene, which encodes the main catalytic component of the reactive oxygen-producing NADPH oxidase complex (Tanaka et al. 2006). This gene is homologous to the mammalian $g p 91^{\text {phox }}$, which plays an essential role in the oxidative burst response of neutrophils to invading pathogens. In contrast to generally asymptomatic wild-type-infected plants, plants infected with the $\Delta$ noxA mutant display severely stunted growth and precocious senescence. Fungal biomass in these interactions is also greatly increased, with loss of the highly regulated hyphal growth pattern characteristic of wild-type interactions. A number of other pathways have also been shown to play an essential role in maintaining the mutualistic association between $E$. festucae and perennial ryegrass. These include the stress-activated mitogen-activated protein kinase $s a k A$ (Eaton et al. 2010) and transcription factor proA (Tanaka et al. 2013). Mutants defective in $s a k A$ induce host stunting and precocious senescence similar to but less severe than the $\Delta$ noxA mutant. These mutants also induce dramatic changes in host development (Eaton et al. 2010). Disruption of proA also leads to severe host stunting and even earlier host senescence (Tanaka et al. 2013). The availability of E. festucae strains at each end of the symbiotic spectrum (mutualism and antagonism) provides a unique opportunity to investigate the differences in gene expression between these two states, and the molecular differences between them. This opportunity has been exploited using high-throughput next-generation RNA sequencing to examine differences in fungal gene expression between the $\Delta s a k A$ mutant association and the wild-type association (Eaton et al. 2010). This study identified over 1,200 fungal genes, approximately $11 \%$ of the total gene set, that are differentially expressed between the two symbiotic states. To reduce this large number to a core gene set distinguishing these two physiological states, we extend this transcriptomic approach by performing high-throughput RNA sequencing of two additional antagonistic mutants, $\triangle$ noxA and $\triangle p r o A$, defective in different pathways. 


\section{RESULTS}

A core fungal gene set distinguishing mutualistic from antagonistic symbiotic states.

To identify genes whose expression is altered between the mutualistic wild-type association and antagonistic mutant associations (host interaction phenotypes illustrated in Figure 1), high-throughput mRNA sequencing was performed on two biological replicates for each of the wild-type, $\triangle$ noxA, and $\triangle p r o A$ associations. An improved version of the E. festucae gene models (EfM3) (Schardl et al. 2013) has been released since the original $\triangle s a k A$ study (Eaton et al. 2010); therefore, the $\triangle s a k A$ and associated wild-type reads were remapped to the new gene models in exactly the same way as for $\Delta$ noxA and $\triangle p r o A$. Differences between the three mutant data sets and their associated wild-type samples (Supplementary Datasets 1 to 4) were then compared to identify a core set of E. festucae genes that show common differential expression patterns in all three mutants (Supplementary Fig. 1). Only those genes that exhibited differential expression in the same direction (i.e., all upregulated or all downregulated) were included. This analysis identified a core gene set of 182 genes, based on statistically significant differences (corrected $P<0.05$ ) and a twofold change cutoff (Fig. 2) (Supplementary Dataset 5). Of the 182 genes in the core gene set, 143 were upregulated and 39 downregulated in the antagonistic mutants relative to the wild type. To gain insight into the nature of these gene expression changes, genes were sorted into biological process and primary molecular function gene ontology (GO) categories (Fig. 3). However, 57\% of the differentially expressed genes had no known biological process and $37 \%$ had no known molecular function, reflecting the large number of fungal genes yet to be functionally characterized. GO enrichment analysis identified only a single category enriched in the core gene set, iron ion binding (GO:0005506, $P<0.0001$ ). However, manual annotation of predicted function for the 182 differentially expressed genes based on protein homology search results identified six key areas of cell function and metabolism in which fungal gene expression was either increased (primary metabolism, membrane transport, cell wall biosynthesis, and host cell wall degradation) or decreased (secondary metabolism and host signaling) (Fig. 4). A more detailed analysis of the gene expression changes associated with these six cellular processes in the 182 core gene set is presented below.

\section{Changes in primary metabolism gene expression.}

A general upregulation of primary metabolic gene expression was identified in the antagonistic mutants (Table 1). This includes two genes putatively involved in nitrogen metabolism, with homology to Saccharomyces cerevisiae ARO8, encoding

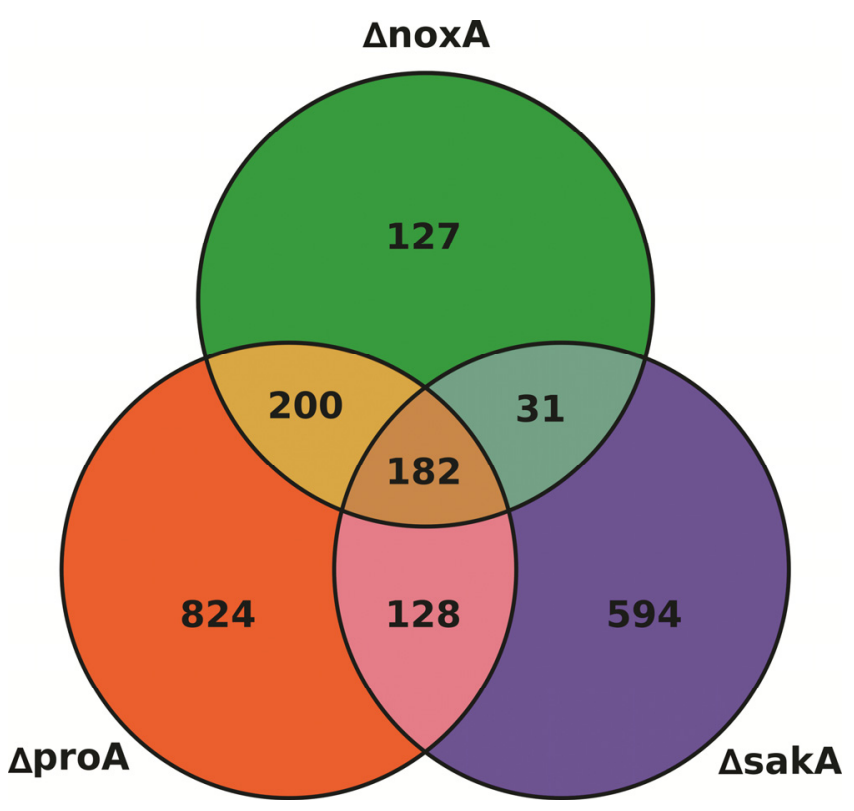

Fig. 2. Distribution of differentially expressed Epichloë festucae genes among the three antagonistic mutants. Venn diagram showing the number of differentially expressed genes shared by the antagonistic mutants. Differentially expressed genes are defined as those displaying a statistically significant, greater than twofold difference in expression relative to the wild-type strain.

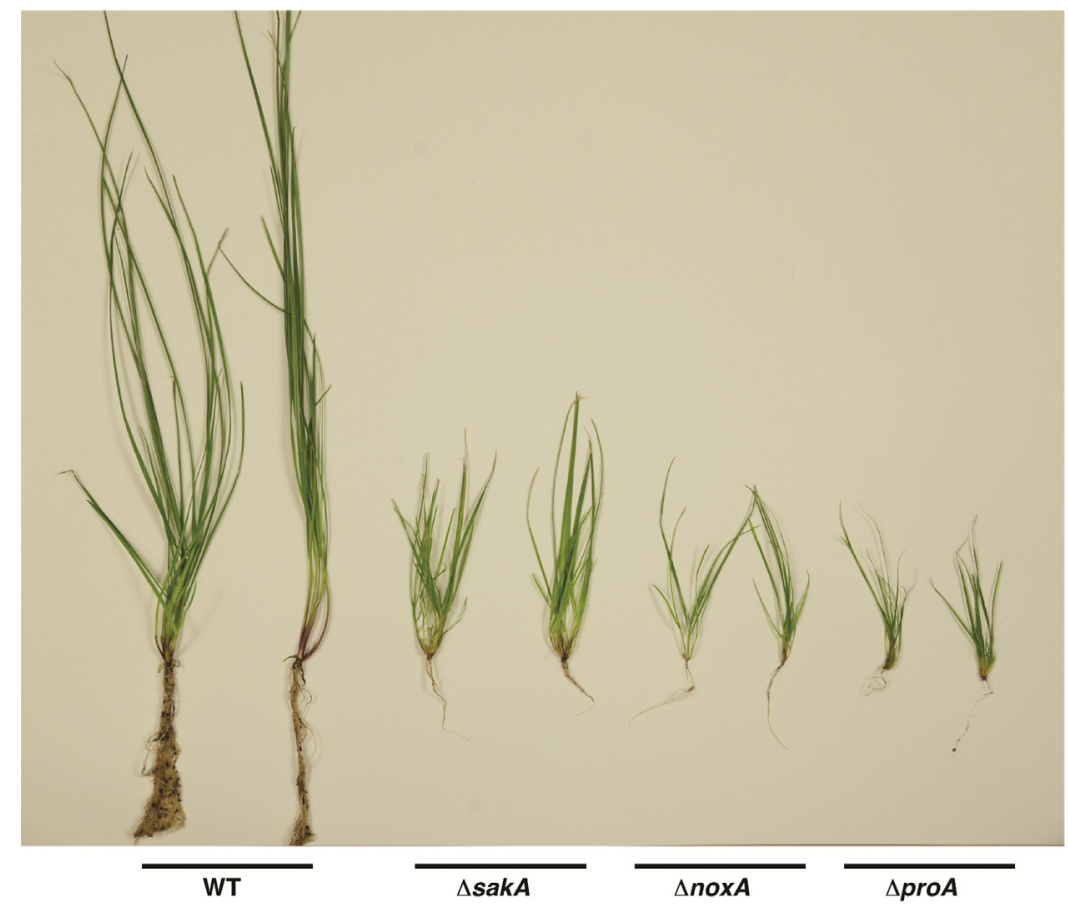

Fig. 1. Plant-interaction phenotype of the Epichloë festucae antagonistic mutants. Photograph showing Lolium perenne plants infected with wild-type E. festucae (WT) and $\triangle s a k A, \triangle$ noxA, and $\triangle p r o A$ mutant strains. Photographs were taken 8 weeks after inoculation. 
an aromatic aminotransferase (Iraqui et al. 1998), and GDH2, encoding an NAD+-dependent glutamate dehydrogenase (Miller and Magasanik 1990). Similarly, two genes involved in thiamine biosynthesis, homologous to THI4, encoding a thiazole synthase (Praekelt and Meacock 1992), and THI13 (Wightman and Meacock 2003) of $S$. cerevisiae, and a homologue of the $S$. cerevisiae invertase gene SUC2 (Carlson and Botstein 1982), were also upregulated in the antagonistic mutants. To test for changes in nutrient composition, apoplastic fluid was analyzed by gas chromatography mass spectrometry (GC-MS) (Supplementary Dataset 6). This analysis identified significantly lower levels of a monosaccharide sugar and two unknown compounds in the antagonistic mutants (Table 2).
Breakdown of the symbiosis is associated with upregulation of genes for membrane transporters.

Eleven predicted transporter genes were significantly upregulated in the three antagonistic mutants (Fig. 3B), with nine encoding putative major facilitator superfamily (MFS) transporters (Table 3). In total, 111 genes for MFS transporters were identified in E. festucae based on predicted protein domains (Supplementary Dataset 7 ), indicating a significant enrichment in the core gene set $(P<0.001)$. One of the upregulated MFS transporter genes (EfM3.012620) corresponds to the monosaccharide transporter MSTN previously characterized in the asexual derivative of E. festucae, E. festucae var. lolii (=Neotyphodium lolii) (Leuchtmann et al. 2014), and shown

A
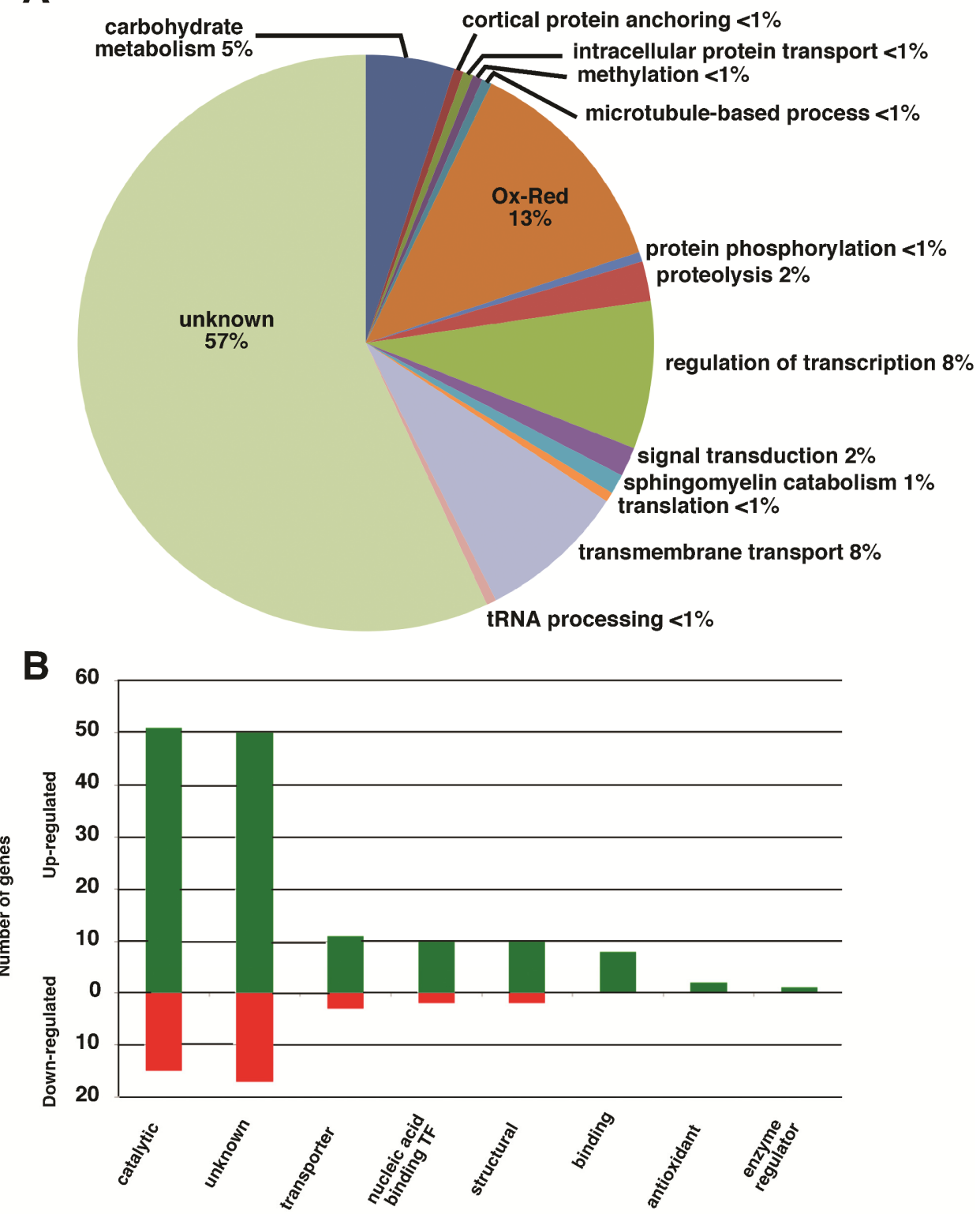

Fig. 3. Differentially expressed fungal genes organized by gene ontology (GO) categories. A, Pie chart showing organization of the triple comparison gene set by 'Biological Process' GO category. Categories are as follows: carbohydrate metabolism (GO:0005975), cortical protein anchoring (GO:0032065), intracellular protein transport (GO:0006886), methylation (GO:0032259), microtubule-based process (GO:0007017), oxidation-reduction (Ox-Red) (GO:0055114), protein phosphorylation (GO:0006468), proteolysis (GO:0006508), regulation of transcription, DNA-dependent (GO:0006355), signal transduction (GO:0007165), sphingomyelin catabolic process (GO:0006685), translation (GO:0006412), transmembrane transport (GO:0055085), tRNA processing (GO:0008033), biological process unknown (non-GO category). B, Graph showing organization of the core gene set by primary 'Molecular Function' GO category. Bars show the number of genes within each category that are up- or downregulated in the antagonistic mutants relative to the wild-type strain. Categories are as follows: antioxidant activity (GO:0016209), binding (GO:0005488), catalytic activity (GO:0003824), enzyme regulator activity (GO:0030234), nucleic acid binding transcription factor activity (GO:0001071), structural molecule activity (GO:0005198), transporter activity (GO:0005215), and unknown (molecular function unknown and Clavicipitaceae unique, non-GO categories). 
to have high affinity for the cell wall sugar mannose and lower affinity for xylose (Rasmussen et al. 2012b). Upregulation of the MSTN gene suggests that the antagonistic mutants may have enhanced ability to take up host-derived nutrients. This is further supported by the observation that two additional sugar transporter genes and two peptide transporter genes were upregulated in all three antagonistic mutants (Table 3). In contrast, a putative malate permease gene, an ABC transporter gene, and a purine transporter gene were all downregulated in the three antagonistic mutants (Table 3 ).

\section{Changes in expression}

\section{of genes for host cell-wall degradation.}

Given that the gene for MSTN, a transporter able to transport the major cell-wall component xylose, was upregulated in the antagonistic mutants, the potential ability of these mutants to hydrolyze host cell-wall components was investigated by a closer analysis of the transcriptomics results. Plant cell walls

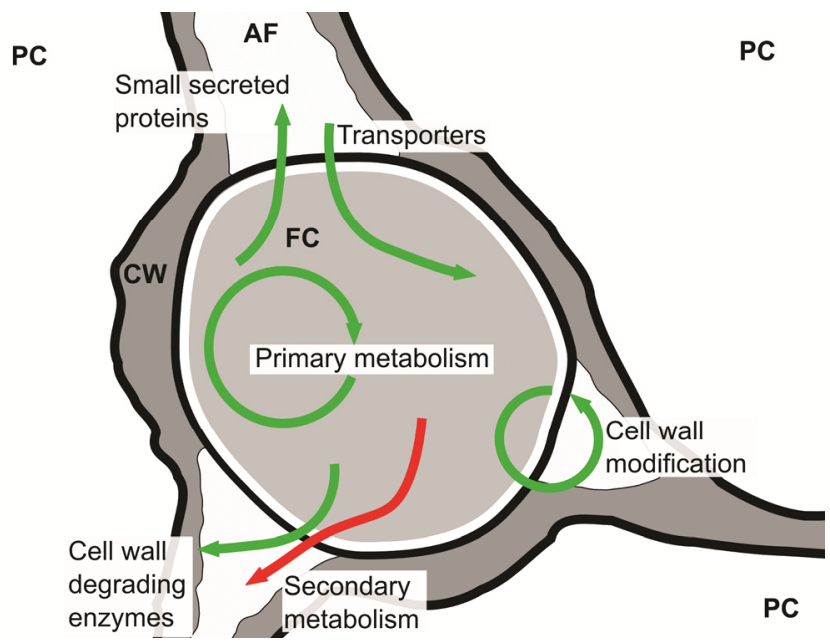

Fig. 4. Schematic illustrating biological processes altered in antagonistic relative to mutualistic states. Six major changes in gene expression displayed by the $\triangle n o x A, \triangle p r o A$, and $\triangle s a k A$ mutants are summarized. Green arrows indicate those processes generally displaying upregulation, whereas red arrows indicate those generally displaying downregulation. $\mathrm{PC}=$ plant cell, $\mathrm{FC}=$ fungal cell, $\mathrm{AF}=$ apoplastic fluid, $\mathrm{CW}=$ cell wall (plant). are mainly composed of cellulose, hemicellulose, pectins, and wall-associated proteins (Di Pietro et al. 2009). CAZome analysis revealed that $E$. festucae contains genes in five of the six CAZy classes (Cantarel et al. 2009): glycoside hydrolases $(n=$ 126), glycosyltransferases $(n=86)$, carbohydrate esterases $(n=$ $51)$, auxiliary activities $(n=28)$, and carbohydrate-binding modules $(n=25)$ (Supplementary Dataset 8$)$. No genes for polysaccharide lyases were identified. Eighteen CAZyme genes were present in the core gene set (Table 4), with genes for carbohydrate esterases, in particular, found to be enriched $(P<0.001)$. Based on the presence of a number of putative plant cell-wall-degrading genes in the core gene set, the potential for degradation of the different components of the host cell wall (cellulose, hemicellulose, pectin, and cutin) by the antagonistic mutants was analyzed further.

Cellulose or hemicellulose degradation. Degradation of cellulose to glucose involves endo- $\beta$-1,4-glucanases, cellobiohydrolases, and P-glucosidases (Di Pietro et al. 2009). E. festucae possesses genes in two of the six CAZy classes involved in degradation of cellulose: one GH12 family (EfM3.043000) and one GH74 family (EfM3.073700). However, expression of these genes is not altered in the antagonistic mutants. In contrast, three genes involved in hemicellulose degradation were upregulated in the antagonistic mutants (Table 4; Fig. 5). Xylan, the main constituent of the hemicellulose component of plant cell walls, is degraded into the monosaccharide xylose via numerous xylanase enzymes (Zhao et al. 2014). The upregulated genes are predicted to encode an endoxylanase (EfM3.040190), homologous to cpxyl2 from Claviceps purpurea (Giesbert et al. 1998); a glycosyl hydrolase (EfM3.037040); and a GH115 family protein (EfM3.018300). A CE5 family acetylxylan esterase gene (EfM3.037435) was also upregulated in the antagonistic mutants (Table 4). Of these four predicted xylan-degrading enzymes, three (EfM3.040190, EfM3.037040, and EfM3.037435) are predicted to contain signal peptides and, therefore, may be secreted and thus have direct access to the host cell wall. This increased potential for xylan degradation by the antagonistic mutants is consistent with the upregulation of the gene for the MSTN mannose/xylose transporter, which would bring degradation products into the fungal cell.

Expression of key genes involved in breakdown of xylose was also investigated (Fig. 5). Xylose breakdown occurs via two distinct branches, initiated by xylose reductase $(x y l 1)$ and

Table 1. Changes in primary metabolic gene expression

\begin{tabular}{|c|c|c|c|c|c|c|}
\hline \multirow[b]{2}{*}{ Model } & \multirow[b]{2}{*}{ Homologue $^{\text {b }}$} & \multirow[b]{2}{*}{ Function } & \multirow[b]{2}{*}{ Reference } & \multicolumn{3}{|c|}{ Fold change $^{a}$} \\
\hline & & & & $\Delta \operatorname{noxA}$ & $\Delta p r o A$ & $\Delta s a k A$ \\
\hline EfM3.009220 & ARO8 & Aromatic aminotransferase & Iraqui et al. 1998 & 2.13 & 3.06 & 3.82 \\
\hline EfM3.013550 & $G D H 2$ & $\mathrm{NAD}(+)$-dependent glutamate dehydrogenase & Miller and Magasanik 1990 & 2.10 & 2.68 & 3.98 \\
\hline EfM3.074710 & $S U C 2$ & Invertase & Carlson and Botstein 1982 & 2.33 & 2.93 & 7.90 \\
\hline EfM3.081920 & $P L C 1$ & Phospholipase C & Yoko-o et al. 1993 & 2.35 & 3.13 & 3.69 \\
\hline EfM3.066730 & YJU3 & Monoglyceride lipase & Heier et al. 2010 & 8.34 & 11.4 & 7.52 \\
\hline EfM3.012680 & THI13 & Thiamine biosynthetic protein & Wightman and Meacock 2003 & 3.22 & 5.60 & 2.71 \\
\hline EfM3.032990 & THI4 & Thiazole synthase & Praekelt and Meacock 1992 & 3.05 & 5.45 & 2.03 \\
\hline
\end{tabular}

${ }^{a}$ Fold changes are relative to the wild type, based on normalized RPMK values.

${ }^{\mathrm{b}}$ Saccharomyces cerevisiae homologue.

Table 2. Gas chromatography mass spectrometry metabolite analysis

\begin{tabular}{|c|c|c|c|c|c|c|c|}
\hline \multirow[b]{2}{*}{ Putative identity } & \multirow[b]{2}{*}{ WT avg. ${ }^{a}$} & \multirow[b]{2}{*}{$\Delta$ sakA avg. ${ }^{a}$} & \multirow[b]{2}{*}{$\Delta$ noxA avg. ${ }^{a}$} & \multirow[b]{2}{*}{$\triangle p r o A$ avg. ${ }^{a}$} & \multicolumn{3}{|c|}{ Probability, WT vs. } \\
\hline & & & & & $\Delta s a k A$ & $\Delta n o x A$ & $\Delta p r o A$ \\
\hline Sample_E114_Splitless_9 (unknown) & 555 & 401 & 335 & 227 & 0.03 & 0.01 & 0.01 \\
\hline Monosaccharide sugar & 15,681 & 7,878 & 8,134 & 7,950 & 0.03 & 0.03 & 0.04 \\
\hline Parahydroxybenzoic acid & 42 & 0 & 0 & 0 & 0 & 0 & 0 \\
\hline Sample_E119_Splitless_9 (unknown) & 152 & 0 & 0 & 0 & 0.02 & 0.02 & 0.02 \\
\hline
\end{tabular}

${ }^{\mathrm{a}} \mathrm{WT}=$ wild type and avg. = average. Values are in arbitrary units obtained by dividing the peak of interest by that of the ribitol internal standard. 
D-xylose-NADP ${ }^{+}$dehydrogenase. Xylose reductase converts D-xylose to xylitol, whereas D-xylose-NADP ${ }^{+}$dehydrogenase converts D-xylose to D-xylonolactone (Johnsen et al. 2009). The gene for xylose reductase in E. festucae (EfM3.064900) was significantly upregulated in the $\triangle p r o A$ and $\triangle s a k A$ mutants, whereas the gene for $\mathrm{D}$-xylose-NADP ${ }^{+}$dehydrogenase (EfM3.062330) was significantly downregulated in all three antagonistic mutants. These results suggest that any increased xylose degradation by the antagonistic mutants occurs via the xylose reductase branch.

Pectinases. The pectin matrix of plant cell walls consists of a mixture of polysaccharides, of which polygalacturonic acid and rhamnogalacturonan I are the most common, although pectin levels are thought to be very low in grasses (Carpita 1996). Breakdown of pectin involves polygalacturonases, pectate lyases, and pectin methylesterases (Di Pietro et al. 2009). The E. festucae endopolygalacturonase gene (EfM3.061190), homologous to cppg1 and cppg 2 from C. purpurea (Oeser et al. 2002), is upregulated in all three antagonistic mutants and predicted to be secreted (Table 4). A single pectin methylesterase gene (EfM3.008730), homologous to Bcpme1 and Bcpme2 of Botrytis cinerea (Kars et al. 2005; Valette-Collet et al. 2003), was also identified but its expression is unchanged. Interrogation of the E. festucae genome with pectate lyase genes from Fusarium solani (pelA-pelD) (González-Candelas and Kolattukudy 1992; Guo et al. 1995a,b, 1996) failed to identify any homologues, suggesting that E. festucae does not possess genes for pectate lyases.

Cutinases. Cutin, a polyester of n-16 and n-18 hydroxyl and epoxy fatty acids, is the main component of the waxy cuticle layer, which covers the surface of plant tissues (Di Pietro et al. 2009). Cutinases are carbohydrate esterase class CE5 enzymes, for which $E$. festucae possesses four genes, two of which are upregulated in the antagonistic mutants (Table 4). One of these, EfM3.008610, is homologous to the cutinase gene CUT2 of Magnaporthe oryzae (Skamnioti and Gurr 2007), whereas the other, EfM3.037435, as mentioned earlier, is predicted to encode a gene product for xylan degradation.

Table 3. Changes in transporter gene expression

\begin{tabular}{|c|c|c|c|c|c|c|c|c|c|}
\hline \multirow[b]{2}{*}{ Model } & \multirow[b]{2}{*}{ Homologue } & \multirow[b]{2}{*}{ Species } & \multirow[b]{2}{*}{ E-value } & \multirow[b]{2}{*}{ Predicted function } & \multirow[b]{2}{*}{ Class $^{b}$} & \multirow[b]{2}{*}{ Reference } & \multicolumn{3}{|c|}{ Fold change $^{a}$} \\
\hline & & & & & & & $\Delta \operatorname{nox} A$ & $\Delta p r o A$ & $\Delta s a k A$ \\
\hline EfM3.012760 & Mae1 & $\begin{array}{l}\text { Schizosaccharomyces } \\
\text { pombe }\end{array}$ & $2.2 \times 10^{-69}$ & $\begin{array}{l}\text { Malic acid transport } \\
\text { protein }\end{array}$ & Malate permease & Grobler et al. 1995 & -3.1 & -3.0 & -3.2 \\
\hline EfM3.056220 & $\ldots$ & - & $\ldots$ & $\begin{array}{l}\text { ABC multidrug } \\
\text { transporter }\end{array}$ & $\mathrm{ABC}$ & $\ldots$ & -4.3 & -3.3 & -7.2 \\
\hline EfM3.066900 & $\ldots$ & $\ldots$ & $\ldots$ & Purine transporter & $\begin{array}{l}\text { Xanthine/uracil } \\
\text { permease }\end{array}$ & $\ldots$ & -3.7 & -4.3 & -21 \\
\hline EfM3.001270 & Ptr2 & Stagonospora nodorum & $\ldots$ & Peptide transporter & MFS & Solomon et al. 2003 & 2.4 & 2.5 & 12.1 \\
\hline EfM3.007470 & $\ldots$ & $\ldots$ & $\ldots$ & Glucose transporter & MFS & $\ldots$ & 2.3 & 2.4 & 4.8 \\
\hline EfM3.012620 & MSTN & Neotyphodium lolii & 0 & $\begin{array}{l}\text { Monosaccharide } \\
\text { transporter }\end{array}$ & MFS & Rasmussen et al. 2012b & 3.3 & 2.9 & 26 \\
\hline EfM3.025110 & $\ldots$ & $\ldots$ & $\ldots$ & Sugar transporter & MFS & $\ldots$ & 2.5 & 2.4 & 8.4 \\
\hline EfM3.025310 & DIP5 & Saccharomyces cerevisiae & $7.3 \times 10^{-132}$ & $\begin{array}{l}\text { Dicarboxylic amino } \\
\text { acid permease }\end{array}$ & AA permease & Regenberg et al. 1998 & 2.3 & 2.7 & 3.0 \\
\hline EfM3.027570 & Ptr2-like & $\ldots$ & $\ldots$ & Peptide transporter & MFS & $\ldots$ & 2.7 & 3.4 & 8.1 \\
\hline EfM3.035410 & Jen1-like & $\ldots$ & $\cdots$ & $\begin{array}{l}\text { Carboxylic acid } \\
\text { transporter }\end{array}$ & MFS & $\ldots$ & 2.8 & 3.7 & 4.6 \\
\hline EfM3.038860 & $\ldots$ & $\ldots$ & $\ldots$ & Phthalate transporter & MFS & $\ldots$ & 3.4 & 6.6 & 3.8 \\
\hline EfM3.044700 & $\cdots$ & $\cdots$ & $\cdots$ & $\begin{array}{l}\text { MFS multidrug } \\
\text { transporter }\end{array}$ & MFS & $\ldots$ & 2.3 & 3.2 & 5.0 \\
\hline EfM3.050930 & $\ldots$ & $\ldots$ & $\ldots$ & MFS transporter & MFS & $\ldots$ & 6.0 & 6.0 & 15 \\
\hline EfM3.077650 & $\cdots$ & $\cdots$ & $\cdots$ & $\begin{array}{l}\text { 2-oxoglutarate/malate } \\
\text { carrier }\end{array}$ & $\begin{array}{l}\text { Mitochondrial } \\
\text { carrier }\end{array}$ & $\ldots$ & 2.0 & 3.4 & 2.0 \\
\hline
\end{tabular}

${ }^{a}$ Fold changes are relative to the wild type, based on normalized RPMK values.

${ }^{\mathrm{b}}$ MFS = major facilitator superfamily.

Table 4. Changes in CAZyme gene expression

\begin{tabular}{|c|c|c|c|c|c|c|}
\hline \multirow[b]{2}{*}{ Model } & \multirow[b]{2}{*}{ CAZy class } & \multirow[b]{2}{*}{ Predicted function } & \multirow[b]{2}{*}{ Reference } & \multicolumn{3}{|c|}{ Fold change } \\
\hline & & & & $\Delta \operatorname{nox} A$ & $\Delta p r o A$ & $\Delta \operatorname{sakA}$ \\
\hline EfM3.040190 & GH10 & Endoxylanase & Giesbert et al. 1998 & 5.48 & 4.31 & 11.9 \\
\hline EfM3.000810 & GH18/CBM18 & Chitinase & $\ldots$ & -3.98 & -3.82 & -2.88 \\
\hline EfM3.061190 & $\mathrm{GH} 28$ & Endopolygalacturonase & Oeser et al. 2002 & 4.53 & 6.66 & 15.0 \\
\hline EfM3.072380 & GH32 & Glycosyl hydrolase & $\ldots$ & 3.15 & 4.82 & 7.44 \\
\hline EfM3.074710 & GH32 & Invertase & Carlson and Botstein 1982 & 2.33 & 2.93 & 7.90 \\
\hline EfM3.037040 & GH62 & Glycosyl hydrolase & $\ldots$ & 6.28 & 8.79 & 25.5 \\
\hline EfM3.062330 & GH109 & NADP:D-xylose dehydrogenase & $\ldots$ & -3.37 & -4.79 & -7.66 \\
\hline EfM3.018300 & GH115 & Unknown & $\ldots$ & 3.92 & 6.10 & 5.15 \\
\hline EfM3.062310 & GT2 & Polysaccharide synthase & $\ldots$ & -4.57 & -15.3 & -385 \\
\hline EfM3.057950 & GT90 & $\beta$-1,2-Xylosyltransferase & $\ldots$ & 3.10 & 3.19 & 13.1 \\
\hline EfM3.066730 & CE1/CE10 & $\alpha / \beta$ Hydrolase & $\ldots$ & 8.34 & 11.4 & 7.52 \\
\hline EfM3.008610 & CE5 & Cutinase & Skamnioti and Gurr 2007 & 21.1 & 42.0 & 14.1 \\
\hline EfM3.037435 & CE5 & Acetylxylan esterase & $\ldots$ & 4.00 & 7.57 & 19.1 \\
\hline EfM3.021550 & CE10 & $\alpha / \beta$ Hydrolase & $\ldots$ & 3.30 & 6.24 & 2.65 \\
\hline EfM3.041830 & CE10 & $\alpha / \beta$ Hydrolase & $\ldots$ & 2.84 & 4.37 & 6.24 \\
\hline EfM3.057830 & CE10 & Para-nitrobenzyl esterase & $\ldots$ & 2.91 & 3.66 & 3.31 \\
\hline EfM3.000190 & AA2 & L-ascorbate peroxidase & $\ldots$ & 2.45 & 3.72 & 3.37 \\
\hline EfM3.048120 & AA3 & Choline dehydrogenase & $\ldots$ & -4.29 & -4.83 & -17.2 \\
\hline
\end{tabular}


Changes in expression of genes

for fungal cell wall structure and composition.

To investigate whether the antagonistic E. festucae mutants had changes in expression of genes associated with fungal cell wall structure and composition, the expression patterns of genes for cell wall proteins and enzymes and production of cell-wall components were analyzed. Fungal cell walls are mainly composed of the polysaccharides glucan and mannan, chitin, and glycoproteins (Bowman and Free 2006). Expression of the gene encoding the main enzyme involved in production

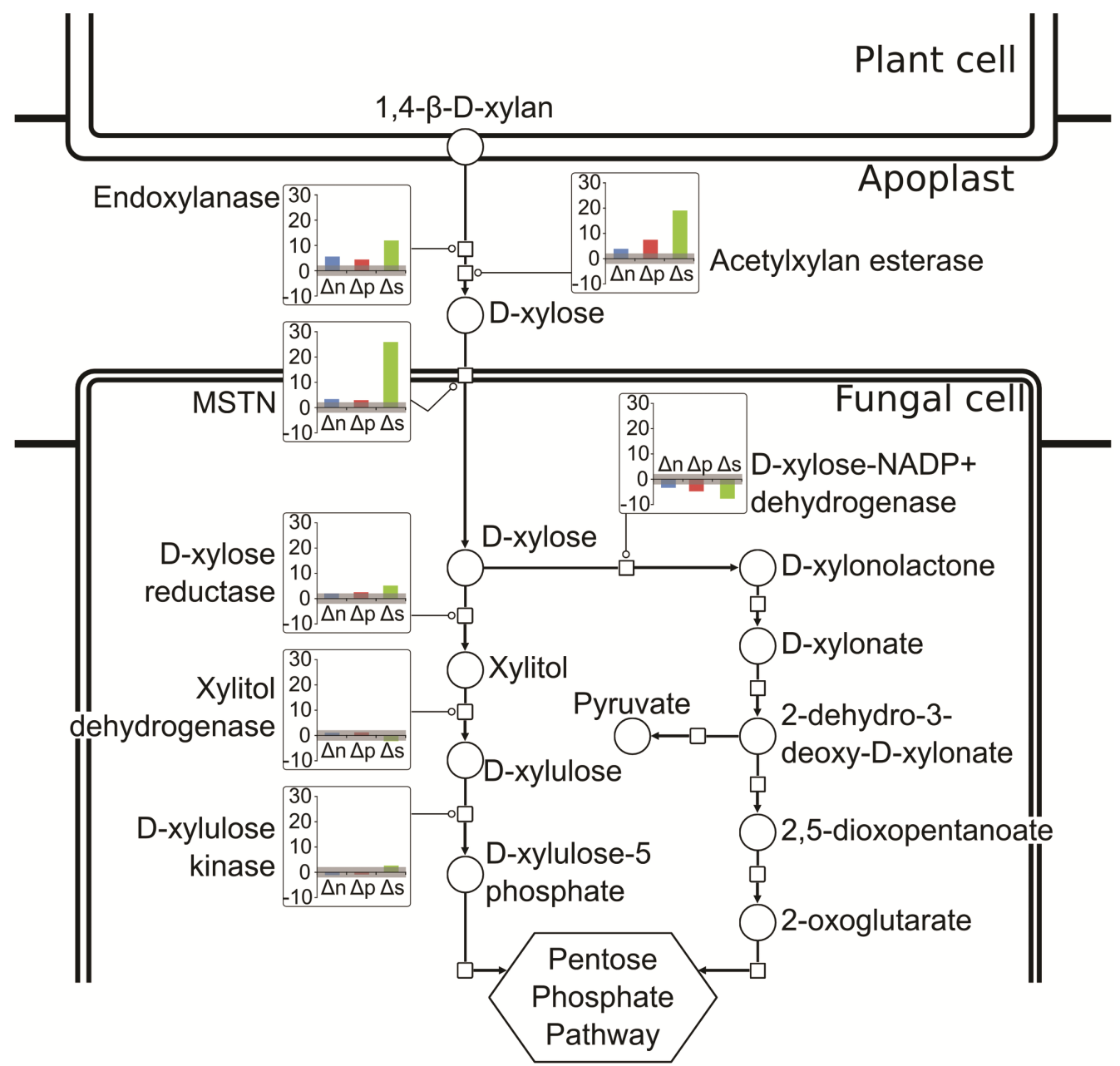

Fig. 5. Changes in expression of genes for xylan breakdown. Schematic showing changes in expression of genes involved in xylan degradation and xylose transport in $\triangle$ noxA (blue bars), $\triangle p r o A$ (red bars), and $\triangle$ sakA (green bars) mutants relative to wild-type Epichloë festucae. Enzymes are shown as squares and substrates are shown as circles.
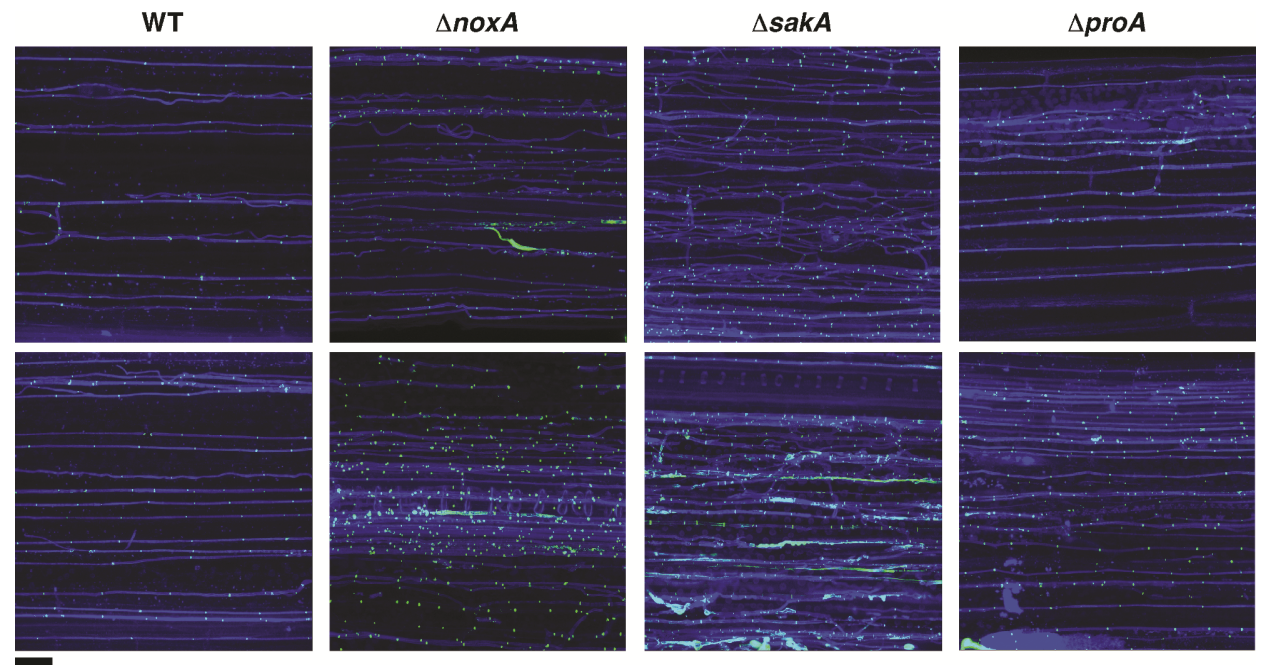

Fig. 6. Analysis of chitin distribution in the antagonistic mutants in planta. Two sets of confocal depth series images (15.1 $\mu \mathrm{m}$ deep) from different independent samples of Epichloë festucae wild-type (WT), $\Delta$ noxA, $\triangle p r o A$, and $\Delta s a k A$ mutant-infected sheath tissue stained with aniline blue and Alexafluor 488WGA. Hyphae appear bright blue and chitin appears bright green. Sheath samples were taken from infected plants 6 weeks after inoculation. Bar $=30 \mu \mathrm{m}$. 
of fungal glucan $\beta$-1,3-glucan synthase was only significantly altered in the $\triangle p r o A$ mutant. Similarly, genes encoding eight putative chitin synthases were identified in E. festucae based on predicted protein domains, and only one was significantly altered in the $\triangle p r o A$ mutant, whereas expression in the other two mutants was unchanged.

In contrast, expression of a chitinase gene was significantly downregulated in all three mutants. To examine chitin localization in these antagonistic mutants, infected plant tissue was stained with Alexa Fluor 488 wheat germ agglutinin (WGA) (Fig. 6). In wild-type associations, fluorescence indicative of chitin localization is generally only visible at the fungal septa, possibly due to masking of chitin present in the cell wall. In contrast, epiphyllous hyphae growing on the surface of infected plant tissues fluoresce along their full length. Examination of the antagonistic mutants in planta revealed patches of fluorescence along hyphae growing within host tissues, particularly in the $\triangle s a k A$ mutant association. There was also a dramatic increase in fluorescently labeled septa in all three mutants, reflecting the increased biomass of these mutants in planta.

A third important constituent of the fungal cell wall are glycoproteins: proteins modified with $\mathrm{N}$ - or $O$-linked oligosaccharides such as galactose and mannan. Ten genes present in the core gene set were predicted to encode cell-wall-associated proteins, including one, EfM3.059380, encoding a product homologous to the glycosylphosphatidylinositol (GPI)-anchored cell wall mannoprotein CwpA from Aspergillus niger (Damveld et al. 2005). EfM3.059380 is among the top 20 most highly upregulated genes in all three mutants. GPI anchors are lipid-oligosaccharide structures that localize proteins to the cell wall. In all, 8 of the 127 predicted GPI-anchored proteins (Supplementary Dataset 9) were present in the core gene set and significantly enriched in this gene set $(P=0.0078)$. This observation may be important because GPI-anchored proteins often act as receptors in mammalian systems (Ilangumaran et al. 1999). One of these GPI-anchored protein encoding genes, which was downregulated in the three mutants, was prtC, a previously characterized gene encoding a subtilisin-like protease (Bryant et al. 2009). In contrast, one of the genes significantly upregulated in the three mutants encodes a homologue of the adhesin Mad2 gene from Metarhizium anisopliae. In M. anisopliae, MAD2 is required for adherence to plant surfaces (Wang and St Leger 2007), suggesting a possible role for the product of this gene in adhesion of E. festucae to host tissues.

\section{Changes in expression of genes \\ for fungal secondary metabolism.}

Given that the genes for several known secondary metabolite biosynthetic pathways were shown previously to be downregulated in the $\Delta s a k A$ mutant (Eaton et al. 2010), expression of these genes in the other two antagonistic mutants was also analyzed. Examination of genes involved in production of ergot alkaloids (eas cluster genes) (Fleetwood et al. 2007) revealed that, similar to $\triangle s a k A, 5$ of the 11 eas genes were significantly downregulated in the $\triangle$ noxA mutant (Fig. 7A). In contrast, only easA was significantly downregulated in $\triangle p r o A$.

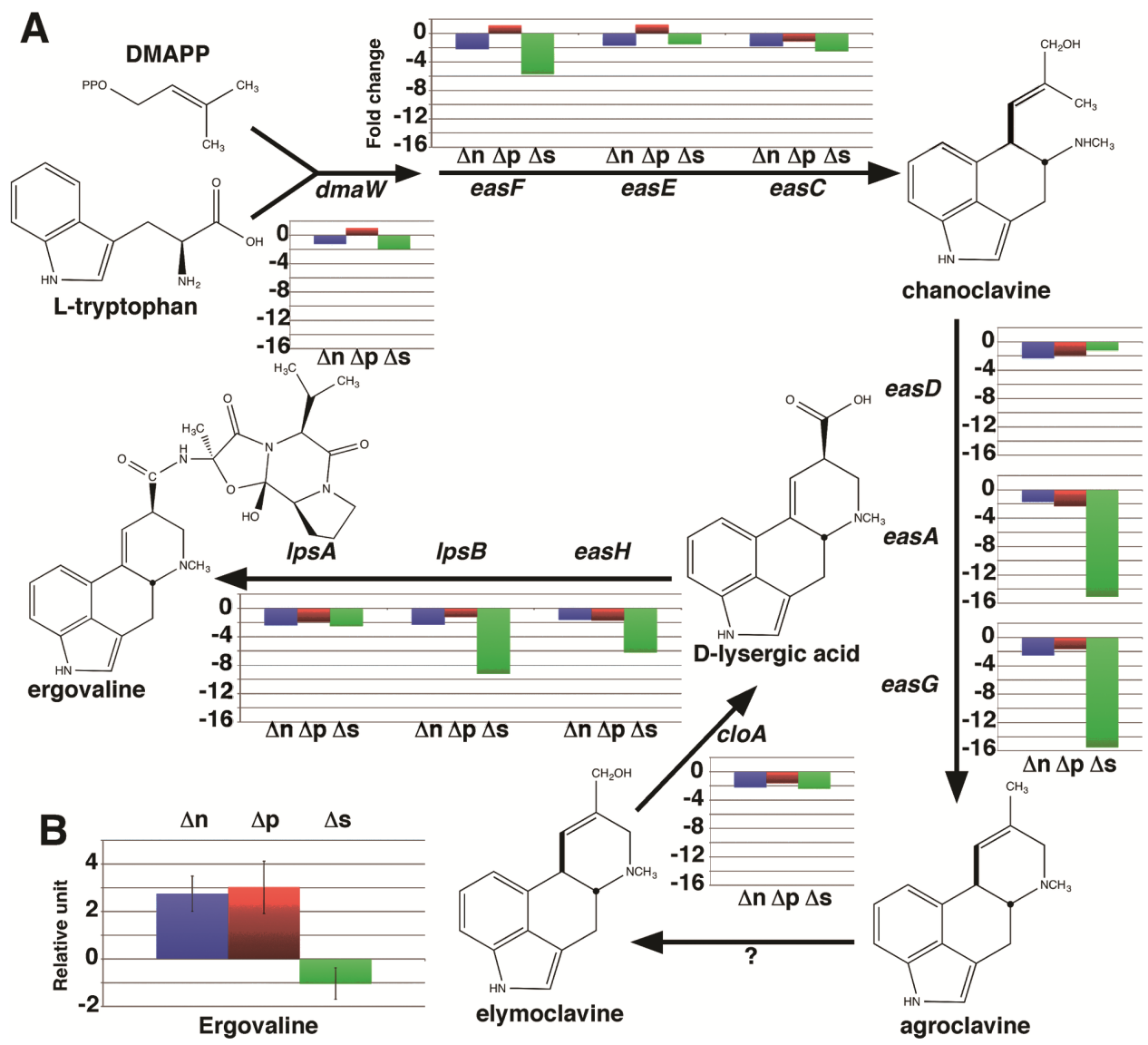

Fig. 7. Changes in ergot alkaloid biosynthesis gene expression and metabolite levels. A, Schematic showing the ergot alkaloid biosynthetic pathway of Epichloë festucae (Schardl et al. 2006, 2013) with changes in expression of biosynthetic genes in $\Delta$ noxA (blue bars), $\Delta$ proA (red bars), and $\Delta$ sakA (green bars) mutants relative to wild-type E. festucae. DMAPP = dimethylallyl pyrophosphate. B, Liquid chromatography tandem mass spectrometry analysis of ergot alkaloids in ryegrass plants infected with wild-type (WT) and $\Delta s a k A, \Delta$ noxA, and $\Delta p r o A$ mutant strains. Values for ergovaline were normalized to plant tissue dry weight and parts per million (ppm) determined using ergotamine as an internal standard. WT levels were assigned a value of 0 , and all other levels are presented relative to WT. Bars represent mean \pm standard error of the mean. 
Liquid chromatography tandem mass spectrometry (LCMS/MS) analysis detected chanoclavine, an early intermediate in ergovaline biosynthesis, in the three antagonistic mutants but not in the wild type. However, no significant differences in the levels of ergovaline were observed (Fig. 7B).

Expression of genes encoding enzymes for the biosynthesis of the indole-diterpene lolitrem B (ltm cluster genes) (Young et al. 2005, 2006) were downregulated in the $\Delta$ noxA mutant, similar to the $\triangle s a k A$ mutant (Fig. 8A), but only ltmE expression was significantly changed. Similarly, only $\mathrm{ltm} E$ was significantly downregulated in the $\triangle p r o A$ mutant. LC-MS/MS analysis revealed that levels of lolitrem $\mathrm{B}$ and its precursors lolitriol and lolitrem $\mathrm{E}$ were significantly reduced in the $\Delta s a k A$ mutant (Fig. 8B). However, levels in the other two mutants were not significantly different from the wild type.

A search of the E. festucae genome to find clusters of genes that were differentially expressed between the wild type and mutants identified three uncharacterized putative secondary metabolism clusters. One of these clusters, downregulated in all three antagonistic mutants, is predicted to contain a single module nonribosomal peptide synthetase (Table 5). Microsynteny analysis of this locus in a range of Clavicipitaceae species shows that this seven-gene cluster is restricted to the genus Epichlö̈ (Fig. 9). Genes of the second uncharacterized cluster are upregulated in the antagonistic mutants and include a gene encoding a putative P450 monooxygenase (Supplementary Table 1). The third cluster of genes is also upregulated in the antagonistic mutants and includes a gene encoding a tyrosinase, suggesting that this cluster may be involved in melanin biosynthesis (Supplementary Table 2). Interestingly, the recently identified insect toxin gene, fitD, putatively transferred from bacteria to a common ancestor of Epichlö̈ spp. (Ambrose et al. 2014), was also downregulated in all three symbiotic mutants.

\section{Symbiont-host communication.}

Almost $37 \%$ of the core gene set (67 genes) had no known molecular function. Twenty-nine of these genes are predicted to encode proteins smaller than 200 amino acids. Of these, 14 are predicted to contain a signal peptide but no transmembrane

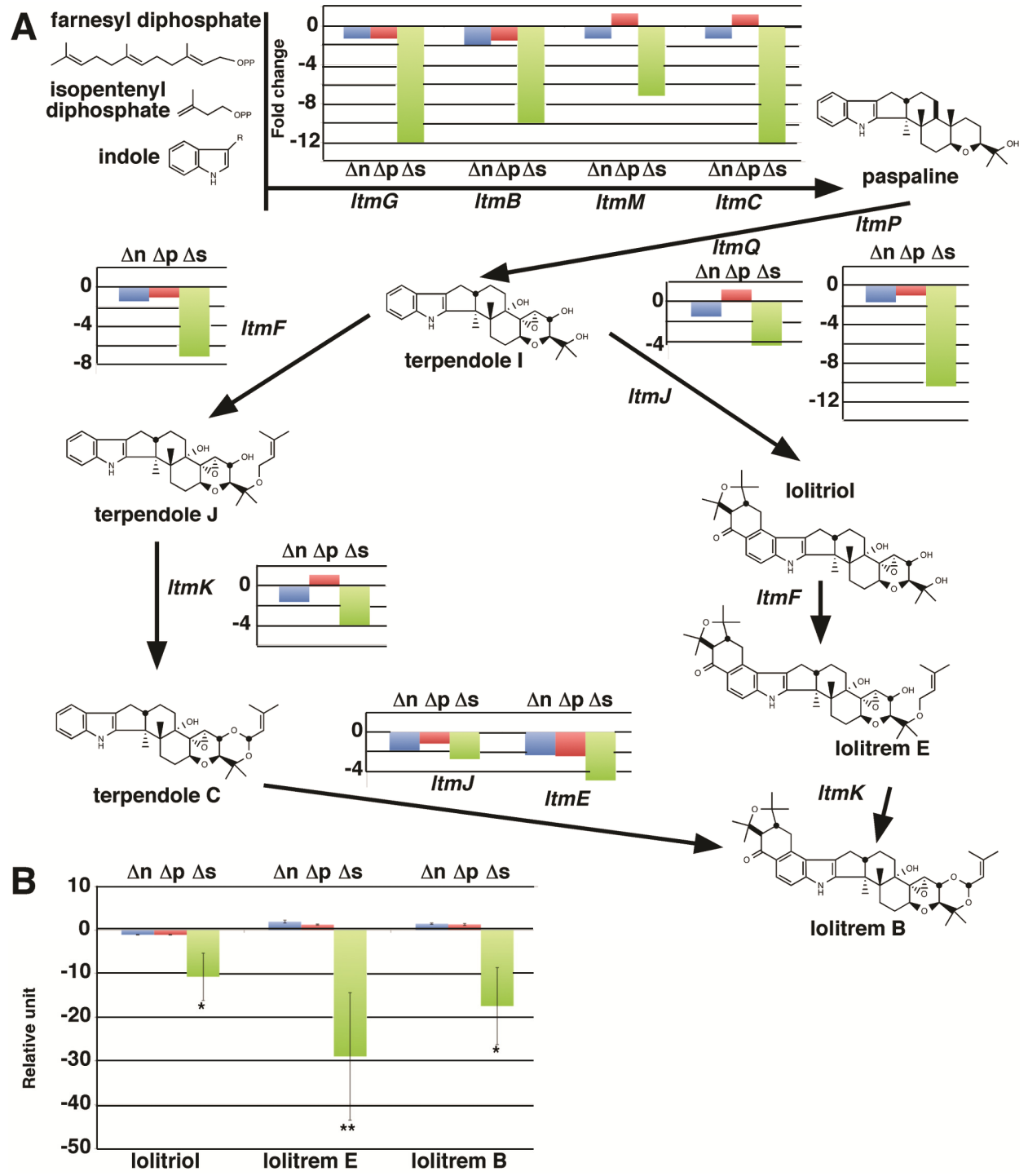

Fig. 8. Changes in lolitrem B biosynthesis gene expression and metabolite levels. A, Schematic showing the lolitrem B biosynthetic pathway of Epichloë festucae (Saikia et al. 2012) with changes in expression of biosynthetic genes in $\Delta$ noxA (blue bars), $\Delta p r o A$ (red bars), and $\Delta$ sakA (green bars) mutants relative to wild-type E. festucae. B, Liquid chromatography tandem mass spectrometry analysis of indole-diterpenes in ryegrass plants infected with the wild type (WT) and $\triangle s a k A, \Delta$ noxA, and $\triangle p r o A$ mutant strains. Values for lolitrem B, and its intermediates lolitriol and lolitrem E, were normalized to plant tissue dry weight. WT levels were assigned a value of 0 , and all other levels are presented relative to WT. Bars represent mean \pm standard error of the mean. Statistical significance in comparison with the WT was determined using Student's $t$ test ( $*$ indicates $0.05 \geq P>0.01$ and $* *$ indicates $0.01 \geq P>0.001$ ). 
domain (Table 6). Therefore, the products of these genes are likely to be small-secreted proteins (SSPs), which may communicate with the host for maintenance of mutualism or suppression of host defenses, similar to effector proteins of phytopathogenic fungi (Rep 2005). Of these 14 putative SSP genes, 10 were upregulated and 4 downregulated in all three antago- nistic mutants. Analysis of the entire gene set of E. festucae Fl1 identified 158 putative SSP genes (Supplementary Dataset $10)$, with a significant enrichment of this gene class in the core gene set $(P<0.0001)$. This implies that SSPs may play an important role in controlling the mutualistic and pathogenic symbiotic states.

Table 5. Putative novel secondary metabolism gene cluster identified by co-expression patterns $\mathrm{s}^{\mathrm{a}}$

\begin{tabular}{|c|c|c|c|c|c|}
\hline Model & Predicted function & Number ${ }^{b}$ & Fold change $\Delta$ noxA & Fold change $\triangle p r o A$ & Fold change $\Delta s a k A$ \\
\hline EfM3.056130 & Hypothetical & 1 & -1.62 & -1.15 & 2.54 \\
\hline EfM3.056150 & Metacaspase & 2 & -1.44 & -1.07 & -1.04 \\
\hline EfM3.056160 & Spindle pole body protein & 3 & -1.43 & 1.46 & -1.04 \\
\hline EfM3.056170 & F-box protein & 4 & 1.24 & 1.70 & -1.23 \\
\hline EfM3.056180 & Ubiquitin carboxyl-terminal hydrolase & 5 & -1.11 & 1.03 & -1.13 \\
\hline EfM3.056190 & Nucleoporin & 6 & 1.21 & 1.73 & -1.18 \\
\hline EfM3.056200 & Pre-rRNA processing protein & 7 & -1.09 & 1.06 & 1.06 \\
\hline EfM3.056220 & $\mathrm{ABC}$ transporter & 8 & -4.25 & -3.31 & -7.23 \\
\hline EfM3.056230 & Nonribosomal peptide synthetase & 9 & -5.54 & -6.42 & -16.4 \\
\hline EfM3.056240 & Haloacid dehalogenase-like hydrolase & 10 & -4.66 & -3.50 & -5.36 \\
\hline EfM3.062340 & Mitochondrial substrate carrier protein & 11 & -1.67 & -2.36 & -2.36 \\
\hline EfM3.062330 & Xylose dehydrogenase & 12 & -3.37 & -4.79 & -7.66 \\
\hline EfM3.062320 & Oxidoreductase & 13 & -1.39 & -9.96 & -67.5 \\
\hline EfM3.062310 & Polysaccharide synthase & 14 & -4.57 & -15.3 & -385 \\
\hline EfM3.062300 & Hypothetical & 15 & -1.17 & 1.07 & -1.16 \\
\hline EfM3.057930 & Coenzyme A transferase & 16 & 1.43 & 1.94 & 1.51 \\
\hline EfM3.044810 & Hypothetical & 17 & 1.02 & -1.05 & 1.18 \\
\hline No EfM3 model & Hypothetical & 18 & & $\ldots$ & $\ldots$ \\
\hline EfM3.044800 & Casein kinase substrate phosphoprotein & 19 & 1.03 & 1.19 & 2.40 \\
\hline
\end{tabular}

${ }^{a}$ Bold values indicate those genes that are greater than twofold differentially expressed and statistically significant. Genes of the predicted cluster are in italics.

${ }^{\mathrm{b}}$ Indicates numbering on Figure 9.

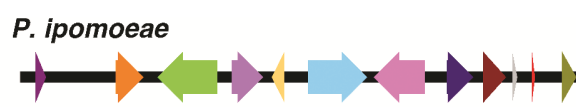

A. take

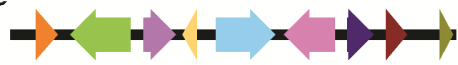

\section{C. fusiformis}

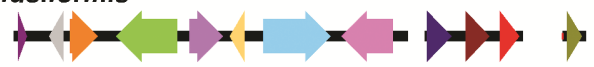

C. paspali

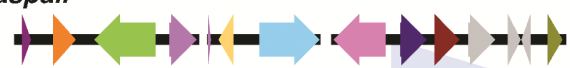

E. typhina

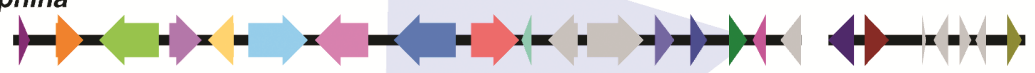

E. brachyelytri

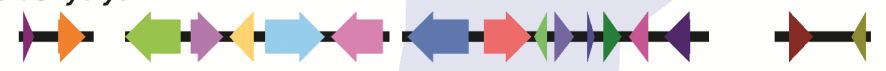

E. elymi

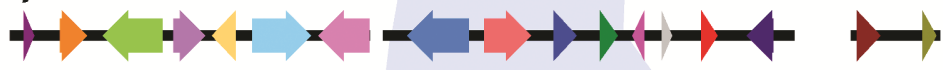

E. amarillans

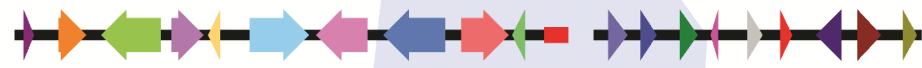

E2368

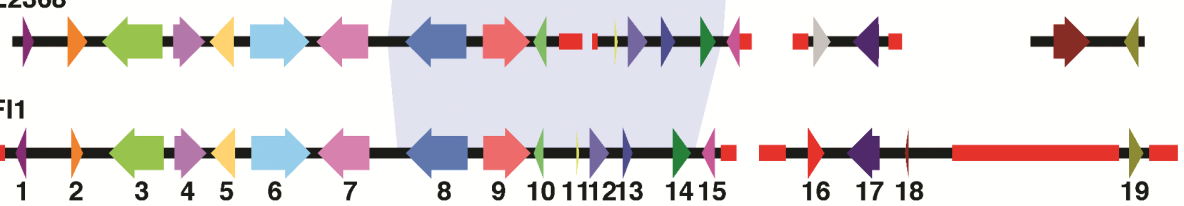

Fig. 9. Novel cluster analysis. Schematic displaying the EfM3.056230 nonribosomal peptide synthetase locus of Epichloë typhina, E. brachyelytri, E. glyceriae, E. elymi, E. amarillans, E. festucae E2368, and E. festucae Fl1. The corresponding locus in Periglandula ipomoeae, Aciculosporium take, Claviceps fusiformis, and C. paspali is also shown. Homologous genes are shown in the same color. Gene numbers shown for Fl1 apply to all species and are described in Table 5. Blue shading indicates the position of the seven genes of the Fl1 symbiotically regulated cluster (genes 8 to 14) and their positions in other Epichloë spp. These genes are absent in the non-Epichloë spp., although flanking genes are present. Red bars represent regions of repetitive DNA. 


\section{DISCUSSION}

Interactions between Epichlö̈ spp. and cool-season grasses are generally referred to as mutually beneficial (Schardl et al. 2004). However, in response to changes in host development or changes in fungal genotype (Eaton et al. 2010; Tanaka et al. 2006, 2013), these associations can shift along the symbiotic spectrum toward a more antagonistic interaction. This study identifies a core set of 182 E. festucae genes that are differentially expressed between mutualistic and pathogenic states using three mutants that disrupt the symbiotic interaction with $L$. perenne. Analysis of the putative functions of the genes upregulated in this core gene set highlighted primary metabolism, peptide and sugar transport, and host cell wall degradation, all changes indicative of a nutrient-starved state in the antagonistic mutants. We hypothesize that this starvation response may be triggered by an inability of these mutants to form a restricted hyphal network within the host, perhaps due to defects in hyphal fusion (Kayano et al. 2013; Tanaka et al. 2013), leading to proliferative growth (Eaton et al. 2010; Tanaka et al. 2006, 2013) and dramatically increased nutrient requirements.

Expression changes displayed by the antagonistic mutants suggest that levels of a variety of nutrients are limiting in planta. For example, a number of genes with functions indicative of nitrogen limitation showed elevated expression in the antagonistic mutants. This includes genes encoding a peptide transporter homologous to PTR2 of Stagonospora nodorum (Solomon et al. 2003), an amino acid permease homologous to Saccharomyces cerevisiae DIP5, and an $\mathrm{NAD}^{+}$-dependent glutamate dehydrogenase homologous to $S$. cerevisiae GDH2 (Miller and Magasanik 1991), all of which are induced by low nitrogen (Miller and Magasanik 1991; Regenberg et al. 1998; Solomon et al. 2003). Similarly, expression of homologues of the thiamine-repressed THII3 and THI4 of S. cerevisiae (Maundrell 1990; Praekelt and Meacock 1992; Praekelt et al. 1994; Wightman and Meacock 2003) was elevated in the antagonistic mutants, suggestive of low thiamine levels in planta. Elevated expression of a homologue of the S. cerevisiae SUC2 invertase gene, which is induced by low glucose (Ozcan et al. 1997), and upregulation of three putative sugar transporter genes, combined with the detection of lower levels of a monosaccharide sugar in apoplastic fluid from the antagonistic mutants, suggests that sugar levels may also be limiting. The enrichment of the iron ion-binding GO category in the set of genes upregulated in the antagonistic mutants suggests that iron levels may also be a limiting factor. This is consistent with a recent study showing that deletion of an E. festucae iron siderophore leads to loss of a mutualistic interaction with perennial ryegrass (Johnson et al. 2013). The induction of a nutrient stress response in the antagonistic mutants is particularly interesting, because nutrient stress has been linked to virulence in phytopathogenic fungi. For example, nitrogen limitation induces expression of the avirulence gene $a v r 9$ in the tomato pathogen Cladosporium fulvum (van den Ackerveken et al. 1994), and many other $C$. fulvum genes induced by starvation in culture are also induced during growth in planta (Coleman et al. 1997). Additionally, transcriptomic profiling of the rice blast pathogen Magnaporthe oryzae during growth in planta and under nutrient-limiting conditions in culture revealed that $M$. oryzae is likely nutrient deprived during invasive growth (Mathioni et al. 2011). The inability of these mutants to undergo cell-cell fusion in planta may trigger a nutrient stress response that results in proliferative growth and increased expression of genes with functions such as degradation of host tissues that allow the fungus to gain access to more nutrients.

The upregulation of genes encoding enzymes that degrade host cell walls in E. festucae antagonistic mutants, possibly a response to survive starvation conditions, is one of many observed changes consistent with an increase in pathogenicrelated gene expression. However, we note that these mutants remain biotrophic and do not penetrate host cells. In contrast to mycorrhizae, which contain a very restricted set of host cellwall-degrading enzymes (CWDE) (Martin et al. 2008; Tisserant et al. 2012), E. festucae possesses genes encoding a variety of cellulases, xylanases, cutinases, and pectinases. Of particular interest is a GH10 family endoxylanase gene upregulated in the antagonistic mutants. GH10 enzymes degrade hemicellulose present in the plant cell wall (Zhao et al. 2014), and genes for this class of enzymes are not present in the genomes of the mycorrhizal fungi Laccaria bicolor and Glomus intraradices (Martin et al. 2008; Tisserant et al. 2012). Additionally, a number of the putative CWDE genes upregulated in the antagonistic mutants are homologous to genes essential for phytopathogenicity in other species (Oeser et al. 2002; Skamnioti and Gurr 2007). This enhanced degradative potential in comparison with mycorrhizal fungi may reflect the lifestyle of E. festucae, which requires the ability to degrade host cell walls for formation of epiphyllous hyphae (Moy et al. 2000; Scott et al. 2012) and development of stromata on the flag leaf of the host to cause "choke" disease (Lam et al. 1995). However, the gene content of the genome of E. festucae limits its potential as a pathogen because it lacks some important host CWDE genes possessed by phytopathogenic fungi, such as those for polysaccharide lyases and $\mathrm{GH} 6 / \mathrm{GH} 7$ family cellulases. In addition to the suite of CWDE genes upregulated in the antagonistic mutants, a number of other hydrolase genes were also upregulated. These results, taken together with the observation that transporter genes are upregulated, suggests that there is increased uptake of host-derived nutrients to support the proliferative growth of these mutants. An upregulation of hydrolase genes during infection is also seen in phytopathogenic fungi (Meinhardt et al. 2014; O'Connell et al. 2012).

In addition to an increase in expression of putative degradative enzyme genes in the symbiotic mutants, there are also a number of changes in cell-wall-associated gene expression that are consistent with a pathogenic physiological state. In particular, genes for GPI-anchored proteins were significantly enriched in the set of genes upregulated in the antagonistic mutants, suggesting changes in cell wall composition of these mutants. GPI-anchored proteins play an important role in the proliferation of F. graminearum in wheat (Rittenour and Harris 2013), and the genes for these proteins are highly expressed during biotrophic and necrotrophic growth of Moniliophthora roreri

Table 6. Putative symbiotically regulated small secreted proteins

\begin{tabular}{|c|c|c|c|c|}
\hline \multirow[b]{2}{*}{ Model } & \multirow[b]{2}{*}{ Size $(\mathbf{a a})^{b}$} & \multicolumn{3}{|c|}{ Fold change $^{a}$} \\
\hline & & $\Delta \operatorname{nox} A$ & $\Delta p r o A$ & $\Delta s a k A$ \\
\hline EfM3.008680 & 119 & 2.76 & 2.27 & 2.55 \\
\hline EfM3.008740 & 169 & 2.99 & 5.34 & 3.59 \\
\hline EfM3.026630 & 105 & 3.03 & 5.70 & 13.1 \\
\hline EfM3.040200 & 96 & 3.92 & 5.17 & 6.12 \\
\hline EfM3.041770 & 64 & 7.89 & 9.31 & 22.7 \\
\hline EfM3.062230 & 106 & 28.9 & 37.7 & 71.5 \\
\hline EfM3.075920 & 89 & 15.8 & 35.4 & 535 \\
\hline EfM3.072390 & 98 & 3.34 & 3.57 & 10.8 \\
\hline EfM3.057440 & 110 & 3.34 & 5.02 & 6.23 \\
\hline EfM3.012120 & 111 & 2.35 & 2.89 & 3.85 \\
\hline EfM3.018200 & 126 & -2.12 & -2.85 & -2.71 \\
\hline EfM3.016770 & 181 & -2.45 & -9.60 & -413 \\
\hline EfM3.062700 & 112 & -6.33 & -7.73 & -59.5 \\
\hline EfM3.014350 & 103 & -2.91 & -16.6 & -8.85 \\
\hline
\end{tabular}

${ }^{a}$ Fold changes are relative to the wild type, based on normalized RPMK values.

b Predicted size in amino acids (aa). 
(Meinhardt et al. 2014). An increase in binding of the fluorescent dye Alexa Fluor 488 WGA to the cell wall of the antagonistic mutants in planta was also observed. This dye interacts with sialic acid and $N$-acetylglucosaminyl residues, and is commonly used as an indicator for chitin (Robin et al. 1986). An increase in dye binding may reflect an increase in chitin levels, due to the downregulation of a chitinase gene in these mutants. Alternatively, it may be due to partial loss of chitin masking by these mutants. Chitin is an essential component of the fungal cell wall but is not present in plants, making it an ideal pathogen-associated molecular pattern. Chitin oligosaccharides released via chitinase activity are perceived by the plant immune system, triggering defense responses. Therefore, many plant-pathogenic fungi have evolved systems to prevent activation of host defenses by chitin (de Jonge et al. 2010; van Esse et al. 2007). An increase in binding in the E. festucae mutants suggests that there is increased accessibility of fungal chitin to host chitinases, indicating that these mutants will likely elicit host defenses. Indeed, the $\Delta s a k A$ mutant has previously been shown to induce expression of host defense-related genes (Eaton et al. 2010).

Concomitant with the increased expression of pathogenicrelated genes is some evidence of a decrease in expression of mutualistic-associated genes. A characteristic feature of the $E$. festucae-perennial ryegrass interaction is the production of bioprotective secondary metabolites by the fungus, which enhance host resistance to insect pests through reduced herbivory (Schardl et al. 2004). Genes encoding the biosynthetic enzymes for the production of the antiherbivore compounds lolitrem B and ergot alkaloids are organized in complex gene clusters and only induced in planta (Fleetwood et al. 2007; Schardl et al. 2013; Young et al. 2005, 2006). Expression of genes in both of these clusters is dramatically reduced in the $\triangle s a k A$ mutant association (Eaton et al. 2010), a result consistent with the decrease in the levels of lolitrem B and build up of the ergot alkaloid precursor chanoclavine. However, in the $\triangle$ noxA and $\triangle p r o A$ mutants, the downregulation of genes for the lolitrem B biosynthetic pathway is much less pronounced, and no reduction in lolitrem B levels is observed. The downregulation of genes for the ergot alkaloid biosynthetic pathway is more marked and a buildup of the precursor chanoclavine is observed; however, there are no statistically significant differences from the wild type in levels of the final product, ergovaline. These results caution that gene expression changes do not necessarily reflect downstream levels of metabolites in any simple manner.

In addition to these well-characterized secondary metabolite gene clusters, this study identified three additional putative secondary metabolism clusters in the antagonistic mutants. This use of RNA sequencing to delineate a secondary metabolism gene cluster was applied successfully in Tolypocladium inflatum to identify the cyclosporin gene cluster (Bushley et al. 2013). Interestingly, one of the gene clusters identified in our study appears to be restricted to Epichloë spp. The possibility that this cluster determines the production of a novel compound with potential bioprotective properties has particularly interesting implications for the pastoral industry.

In addition to secondary metabolism-related genes, it is possible that some of the other genes downregulated in the antagonistic mutants promote a mutualistic interaction. However, $44 \%$ of the genes have no known function, making it difficult to assess their potential roles in mutualism. Four of these genes are predicted to encode SSPs, reminiscent of effectors in phytopathogenic fungi (Rep 2005). Recently, SSPs have also been shown to play an important role in the establishment of mutualistic mycorrhizal interactions (Plett et al. 2011), raising the possibility that these SSPs also play a role in establishing a mutualistic association between E. festucae and perennial ryegrass. Interestingly, one of these four genes, EF320, has previously been shown to be directly regulated by the ProA transcription factor but, in this instance, deletion of the gene has no effect on the interaction with perennial ryegrass (Tanaka et al. 2013). The importance of the other symbiotically regulated SSPs in maintaining mutualism remains to be determined.

The results of this study provide crucial insight into the signaling differences between mutualistic and pathogenic fungusplant interactions. In particular, this study has identified a core gene set whose expression changes significantly and concertedly between these two physiological states. This study lays the foundation for many future studies into the molecular mechanisms underlying plant-fungus mutualism, particularly with respect to the role played by SSPs and the newly identified secondary metabolism cluster.

\section{MATERIALS AND METHODS}

\section{Fungal strains and growth conditions.}

E. festucae strain Fl1 was used in all experimental analyses presented in this study (Supplementary Table 3). For isolation of total RNA in planta, endophyte-free perennial ryegrass seeds (Lolium perenne 'Samson') were germinated on 3\% water agar plates, and inoculated with E. festucae hyphae as previously described (Latch and Christensen 1985). Plants were then grown in a temperature- and light-controlled growth room $\left(22^{\circ} \mathrm{C}, 16 \mathrm{~h}\right.$ of light and $8 \mathrm{~h}$ of dark; Gro-lux bulbs [Sylvania]), and screened for infection as previously described (Tanaka et al. 2005). For examination of chitin localization in planta, leaf sheath tissue from close to the base of infected tillers was cleared overnight in $95 \%$ ethanol, then permeabilized by incubation in $10 \%$ potassium hydroxide for $4 \mathrm{~h}$. Tissue was then vacuum infiltrated with a $1 \%$ aniline blue, $10 \mu \mathrm{g} / \mathrm{ml}$ AF488 Alexafluor-WGA (Molecular Probes) solution for $10 \mathrm{~min}$, and observed using a Leica SP5 DM6000B confocal microscope.

\section{Apoplastic fluid isolation.}

Apoplastic fluid was isolated from wild-type and mutantinfected perennial ryegrass plants using a modification of the method of van Hove and associates (2002). Cut pseudostem and blade tissue was immersed in sterile water in a 50-ml syringe and vacuum infiltrated by repeated cycles of $30 \mathrm{~s}$ of pulling on the plunger, followed by $30 \mathrm{~s}$ of pushing on the plunger. This was repeated until the majority of the tissue became dark green and sank inside the syringe during pressure application. The tissue was then surface dried and placed inside a 1-ml pipette tip. Filled tips were then placed inside a $50-\mathrm{ml}$ falcon tube and centrifuged at 4,300 rpm $(2,000 \times \mathrm{g})$ at $4^{\circ} \mathrm{C}$ for $20 \mathrm{~min}$. The apoplastic fluid was then collected from the bottom of the tube and stored at $-80^{\circ} \mathrm{C}$.

\section{Preparation of RNA and cDNA sequencing.}

Infected pseudostem tissue was harvested 7 weeks postinoculation and snap frozen in liquid nitrogen. Total RNA was then isolated from 0.5 to $0.6 \mathrm{~g}$ (fresh weight) of tissue from a minimum of two plants per biological replicate using TRIzol reagent (Invitrogen). mRNA libraries were generated by Cofactor Genomics, and a 100-nucleotide single-end run was performed according to Illumina guidelines. Libraries were indexed, then pooled and sequenced in six flow cell lanes of an Illumina HiSeq 2000, and the raw results were processed using CASAVA v1.8.2.

\section{RNAseq data analysis.}

To identify genes whose expression is altered between the mutualistic wild-type association and pathogenic mutant asso- 
ciations, high-throughput mRNA sequencing was performed on two biological replicates for each of the wild-type, $\Delta$ noxA, and $\triangle p r o A$ associations. Samples were indexed, pooled, and sequenced across six Illumina HiSeq lanes, thus reducing sample-to-sample technical variation. After sequencing, reads were demultiplexed and sample assignments confirmed by mapping to the hygromycin resistance cassette $(h p h)$ present in $\Delta$ noxA and $\triangle p r o A$ mutant samples, the noxA-deleted region present in wild-type and $\triangle p r o A$ samples, the $p r o A$-deleted region present in wild-type and $\triangle$ noxA samples, and the hph-noxA and $h p h$ proA fusion sequences present in the $\triangle$ noxA and $\triangle p r o A \mathrm{mu}-$ tants, respectively. Linear correlations for each pair of biological replicates were high, explaining 75 to $89 \%$ of the total variance: wild type, $r=0.94, P<0.0001 ; \Delta$ noxA, $r=0.93, P<$ 0.0001 ; and $\triangle$ proA, $r=0.87, P<0.0001$. A new, improved version of the $E$. festucae gene models has been released since the original $\Delta s a k A$ study was performed (Eaton et al. 2010); therefore, the $\triangle s a k A$ and associated wild-type reads were remapped to the new set of gene models (EfM3) (Schardl et al. 2013 ) in exactly the same way as for the $\Delta$ noxA, $\triangle p r o A$, and wild-type samples.

Differentially expressed genes in the three transcriptomic data sets were then compared to identify a core set of $E$. festucae genes that show the same expression pattern in all three symbiotic mutants. Only those genes with differential expression in the same direction (i.e., all upregulated or all downregulated) were included. This produced a core gene set of 182 genes, with a twofold change cutoff and a false discovery rate significance cutoff of $P<0.05$ (Storey and Tibshirani 2003).

To verify whether the number of genes found in the core set was significant (as opposed to chance events), Monte Carlo simulations were performed. A vector of 8,324 genes (equal to the number of gene models used in the transcriptomic analysis) was built. A subset of these genes corresponding to the differentially expressed gene sets for each of the symbiotic mutants was randomly selected (for example, 1,028 for proA and 674 for $s a k A$ for the upregulated gene sets). The number of genes in common between the mutants was then used to compute artificial double and triple comparisons. This step was repeated 1 million times, then compared with the observed number of genes in the double and triple comparisons by placing the real numbers on the distribution of the simulated data. This confirmed that the number of both the upregulated and downregulated genes was significant $\left(P<1 \times 10^{-6}\right)$. For the downregulated genes, the expected range based on the simulated data was 0 to 6 genes (median $=0$ ), whereas the real number identified was 39. For the upregulated genes, the expected range based on the simulated data was 0 to 14 genes $($ median $=$ 3 ), whereas the real number identified was 143 .

\section{Metabolite analyses.}

Primary metabolite analysis of apoplastic fluid samples was performed as previously described (Vincent et al. 2012). Briefly, freeze-dried apoplastic fluid samples were derivatized with the Gerstel MultiPurpose Sampler. Methoximation of carbonyl groups was achieved with incubation and shaking at $37^{\circ} \mathrm{C}$ (90 min, 1,200 rpm) with methylamine- $\mathrm{HCl}(20 \mu \mathrm{l}, 20$ $\mathrm{mg} / \mathrm{ml}$ in pyridine). Trimethylsilyation of polar groups was completed by addition of $30 \mu \mathrm{l}$ of $\mathrm{N}$-trimethylsilyl-N-methyl trifluoroacetamide following by incubation at $37^{\circ} \mathrm{C}$ and shaking for $30 \mathrm{~min}$. GC-MS analysis was then undertaken as previously described (Lowe et al. 2009). Samples were analyzed in splitless and 20:1 split modes in order to obtain quantitative data for all metabolites over the extensive range of concentrations present. The splitless data set was used for metabolites of lower concentration that were not reliably quantified in the split analysis. Metabolite abundances were normalized to the ribitol internal standard and sample weights using AnalyzerPro (SpectralWorks Ltd., Runcorn, U.K.). Mass spectra of compounds found were identified using the publicly available Golm metabolome database (Schauer et al. 2005) and the commercial National Institute of Standards and Technology 08 mass spectral library. Data analyses were carried out using the JMP 8.0.1 statistical package (SAS Institute Inc., Cary, NC, U.S.A.).

Indole-diterpenes and ergot alkaloids were extracted from $L$. perenne pseudostem tissue infected with wild-type E. festucae and the three antagonistic mutants, and analyzed by LCMS/MS as previously described (Rasmussen et al. 2012a). The limit of detection for indole-diterpenes was $0.2 \mathrm{ppm}$ ( 2 units) and for ergot alkaloids was 0.5 ppm (5 units). Peramine was extracted from infected pseudostem tissue using a modification of a previously described method (Hunt et al. 2005; Spiering et al. 2002). A sample of lyophilized grass tissue $(50 \mathrm{mg})$ was extracted for $1 \mathrm{~h}$ with $1 \mathrm{ml}$ of extraction solvent (50\% methanol, with homoperamine nitrate at $2.064 \mathrm{ng} / \mathrm{ml}$ as internal standard). The sample was then centrifuged $(8,000 \times g, 5 \mathrm{~min})$, and a $500-\mu 1$ aliquot of the supernatant was transferred to a highperformance liquid chromatography vial for LC-MS analysis (Rasmussen et al. 2012a). Using this technique, the limit of detection was $1 \mathrm{mg} / \mathrm{g}$.

\section{ACKNOWLEDGMENTS}

This research was supported by a fellowship (to C. J. Eaton) and grant (to M. P. Cox) from the Bio-Protection Research Centre; a grant from the Massey University Research Fund (to C. J. Eaton, M. P. Cox, and B. Scott); a Royal Society of New Zealand Rutherford Fellowship (RDF-10MAU-001 to M. P. Cox); an Australian Research Council Future Fellowship (FT110100698 to P. Solomon); and funding from Massey University (to B. Scott). We thank C. Staerkel, E. Brasell, and W. Duchemin (IFS, Massey University); J. Taylor (Manawatu Microscopy and Imaging Centre, Massey University); and W. Mace (AgResearch) for technical assistance. C. J. Eaton, P.-Y. Dupont, B. Scott, and M. P. Cox designed the research; C. J. Eaton, P.-Y. Dupont, P. Solomon, W. Clayton, B. Scott, and M. P. Cox performed the research; C. J. Eaton, P.-Y. Dupont, P. Solomon, and M. P. Cox analyzed the data; C. J. Eaton, P.-Y. Dupont, B. Scott, and M. P. Cox wrote the paper.

\section{LITERATURE CITED}

Ambrose, K. V., Koppenhofer, A. M., and Belanger, F. C. 2014. Horizontal gene transfer of a bacterial insect toxin gene into the Epichlö fungal symbionts of grasses. Sci. Rep. 4:5562.

Bowman, S. M., and Free, S. J. 2006. The structure and synthesis of the fungal cell wall. BioEssays 28:799-808.

Bronstein, J. L. 1994. Conditional outcomes in mutualistic interactions. Trends Ecol. Evol. 9:214-217.

Bryant, M. K., Schardl, C. L., Hesse, U., and Scott, B. 2009. Evolution of a subtilisin-like protease gene family in the grass endophytic fungus Epichloë festucae. BMC Evol. Biol. 9:168.

Bushley, K. E., Raja, R., Jaiswal, P., Cumbie, J. S., Nonogaki, M., Boyd, A. E., Owensby, C. A., Knaus, B. J., Elser, J., Miller, D., Di, Y., McPhail, K. L., and Spatafora, J. W. 2013. The genome of Tolypocladium inflatum: Evolution, organization, and expression of the cyclosporin biosynthetic gene cluster. PLoS Genet. 9:e1003496. Published online.

Cantarel, B. L., Coutinho, P. M., Rancurel, C., Bernard, T., Lombard, V., and Henrissat, B. 2009. The Carbohydrate-Active EnZymes database (CAZy): An expert resource for glycogenomics. Nucleic Acids Res. 37:D233-D238.

Carlson, M., and Botstein, D. 1982. Two differentially regulated mRNAs with different $5^{\prime}$ ends encode secreted with intracellular forms of yeast invertase. Cell 28:145-154.

Carpita, N. C. 1996. Structure and biogenesis of the cell walls of grasses. Annu. Rev. Plant Physiol. Plant Mol. Biol. 47:445-476.

Coleman, M., Henricot, B., Arnau, J., and Oliver, R. P. 1997. Starvationinduced genes of the tomato pathogen Cladosporium fulvum are also induced during growth in planta. Mol. Plant-Microbe Interact. 10:11061109 
Damveld, R. A., Arentshorst, M., VanKuyk, P. A., Klis, F. M., van den Hondel, C. A., and Ram, A. F. 2005. Characterisation of CwpA, a putative glycosylphosphatidylinositol-anchored cell wall mannoprotein in the filamentous fungus Aspergillus niger. Fungal Genet. Biol. 42:873885

de Jonge, R., van Esse, H. P., Kombrink, A., Shinya, T., Desaki, Y., Bours, R., van der Krol, S., Shibuya, N., Joosten, M. H., and Thomma, B. P. 2010. Conserved fungal LysM effector Ecp6 prevents chitin-triggered immunity in plants. Science 329:953-935.

Di Pietro, A., González-Roncero, I., and Ruiz-Roldán, M. C. 2009. From tools of survival to weapons of destruction: The role of cell-wall degrading enzymes in plant infection. Pages 275-306 in: Plant Relationships. H. B. Deising, ed. Springer-Verlag, Berlin.

Eaton, C. J., Cox, M. P., Ambrose, B., Becker, M., Hesse, U., Schardl, C. L., and Scott, B. 2010. Disruption of signaling in a fungal-grass symbiosis leads to pathogenesis. Plant Physiol. 153:1780-1794.

Egger, K. N., and Hibbett, D. S. 2004. The evolutionary implications of exploitation in mycorrhizas. Can. J. Bot. 82:1110-1121.

Fleetwood, D. J., Scott, B., Lane, G. A., Tanaka, A., and Johnson, R. D. 2007. A complex ergovaline gene cluster in Epichlö endophytes of grasses. Appl. Environ. Microbiol. 73:2571-2579.

Giesbert, S., Lepping, H.-B., Tenberge, K. B., and Tudzynski, P. 1998. The xylanolytic system of Claviceps purpurea: Cytological evidence for secretion of xylanases in infected rye tissue and molecular characterization of two xylanase genes. Phytopathology 88:1020-1030.

González-Candelas, L., and Kolattukudy, P. E. 1992. Isolation and analysis of a novel inducible pectate lyase gene from the phytopathogenic fungus Fusarium solani f. sp. pisi (Nectria haematococca, mating population VI). J. Bacteriol. 174:6343-6349.

Grobler, J., Bauer, F., Subden, R. E., and Van Vuuren, H. J. 1995. The mael gene of Schizosaccharomyces pombe encodes a permease for malate and other C4 dicarboxylic acids. Yeast 11:1485-1491.

Guo, W., Gonzalez-Candelas, L., and Kolattukudy, P. E. 1995a. Cloning of a new pectate lyase gene pelC from Fusarium solani f. sp. pisi (Nectria haematococca, mating type VI) and characterization of the gene product expressed in Pichia pastoris. Arch. Biochem. Biophys. 323:352360

Guo, W., Gonzalez-Candelas, L., and Kolattukudy, P. E. 1995b. Cloning of a novel constitutively expressed pectate lyase gene pelB from Fusarium solani f. sp. pisi (Nectria haematococca, mating type VI) and characterization of the gene product expressed in Pichia pastoris. J. Bacteriol. 177:7070-7077.

Guo, W., Gonzalez-Candelas, L., and Kolattukudy, P. E. 1996. Identification of a novel pelD gene expressed uniquely in planta by Fusarium solani f. sp. pisi (Nectria haematococca, mating type VI) and characterization of its protein product as an endo-pectate lyase. Arch. Biochem. Biophys. 332:305-312.

Heier, C., Taschler, U., Rengachari, S., Oberer, M., Wolinski, H., Natter, K., Kohlwein, S. D., Leber, R., and Zimmermann, R. 2010. Identification of Yju3p as functional orthologue of mammalian monoglyceride lipase in the yeast Saccharomyces cerevisiae. Biochim. Biophys. Acta 1801:1063-1071.

Hunt, M. G., Rasmussen, S., Newton, P. C. D., Parsons, A. J., and Newman, J. A. 2005. Near-term impacts of elevated CO2, nitrogen and fungal endophyte-infection on Lolium perenne L. growth, chemical composition and alkaloid production. Plant Cell Environ. 28:1345-1354.

Ilangumaran, S., Robinson, P. J., and Hoessli, D. C. 1999. Signaling through GPI-anchored receptors. In: GPI-Anchored Membrane Proteins and Carbohydrates. D. C. Hoessli and S. Ilangumaran, eds. Landes BioScience. R. G. Landes, Austin, TX, U.S.A.

Iraqui, I., Vissers, S., Cartiaux, M., and Urrestarazu, A. 1998. Characterisation of Saccharomyces cerevisiae ARO8 and ARO9 genes encoding aromatic aminotransferases I and II reveals a new aminotransferase subfamily. Mol. Gen. Genet. 257:238-248.

Johnson, L. J., Koulman, A., Christensen, M., Lane, G. A., Fraser, K., Forester, N., Johnson, R. D., Bryan, G. T., and Rasmussen, S. 2013. An extracellular siderophore is required to maintain the mutualistic interaction of Epichloë festucae with Lolium perenne. PLoS Pathog. 9:e1003332. Published online.

Johnsen, U., Dambeck, M., Zaiss, H., Fuhrer, T., Soppa, J., Sauer, U., and Schonheit, P. 2009. D-xylose degradation pathway in the halophilic archaeon Haloferax volcanii. J. Biol. Chem. 284:27290-27303.

Kars, I., McCalman, M., Wagemakers, L., and Van Kan, J. A. L. 2005. Functional analysis of Botrytis cinerea pectin methylesterase genes by PCR-based targeted mutagenesis: Bcpme1 and Bcpme 2 are dispensable for virulence of strain B05.10. Mol. Plant Pathol. 6:641-652.

Kayano, Y., Tanaka, A., Akano, F., Scott, B., and Takemoto, D. 2013. Differential roles of NADPH oxidases and associated regulators in polarized growth, conidiation and hyphal fusion in the symbiotic fungus Epichloë festucae. Fungal Genet. Biol. 56:87-97.
Lam, C. K., Belanger, F. C., White, J. F., Jr., and Daie, J. 1995. Invertase activity in Epichloë/Acremonium fungal endophytes and its possible role in choke disease. Mycol. Res. 99:867-873.

Latch, G. C. M., and Christensen, M. J. 1985. Artificial infection of grasses with endophytes. Ann. Appl. Biol. 107:17-24.

Leuchtmann, A., Bacon, C. W., Schardl, C. L., White, J. F., Jr., and Tadych, M. 2014. Nomenclatural realignment of Neotyphodium species with genus Epichlö̈. Mycologia 106:202-215.

Lowe, R. G., Lord, M., Rybak, K., Trengove, R. D., Oliver, R. P., and Solomon, P. S. 2009. Trehalose biosynthesis is involved in sporulation of Stagonospora nodorum. Fungal Genet. Biol. 46:381-389.

Martin, F., Aerts, A., Ahren, D., Brun, A., Danchin, E. G., Duchaussoy, F., Gibon, J., Kohler, A., Lindquist, E., Pereda, V., Salamov, A., Shapiro, H. J., Wuyts, J., Blaudez, D., Buee, M., Brokstein, P., Canback, B., Cohen, D., Courty, P. E., Coutinho, P. M., Delaruelle, C., Detter, J. C., Deveau, A., DiFazio, S., Duplessis, S., Fraissinet-Tachet, L., Lucic, E., Frey-Klett, P., Fourrey, C., Feussner, I., Gay, G., Grimwood, J., Hoegger, P. J., Jain, P., Kilaru, S., Labbe, J., Lin, Y. C., Legue, V., Le Tacon, F. Marmeisse, R., Melayah, D., Montanini, B., Muratet, M., Nehls, U., Niculita-Hirzel, H., Oudot-Le Secq, M. P., Peter, M., Quesneville, H., Rajashekar, B., Reich, M., Rouhier, N., Schmutz, J., Yin, T., Chalot, M., Henrissat, B., Kues, U., Lucas, S., Van de Peer, Y., Podila, G. K., Polle, A., Pukkila, P. J., Richardson, P. M., Rouze, P., Sanders, I. R., Stajich, J. E., Tunlid, A., Tuskan, G., and Grigoriev, I. V. 2008. The genome of Laccaria bicolor provides insights into mycorrhizal symbiosis. Nature 452:88-92.

Mathioni, S. M., Belo, A., Rizzo, C. J., Dean, R. A., and Donofrio, N. M. 2011. Transcriptome profiling of the rice blast fungus during invasive plant infection and in vitro stresses. BMC Genomics 12:49.

Maundrell, K. 1990. nmtl of fission yeast. A highly transcribed gene completely repressed by thiamine. J. Biol. Chem. 265:10857-10864

Meinhardt, L. W., Costa, G. G., Thomazella, D. P., Teixeira, P. J., Carazzolle, M. F., Schuster, S. C., Carlson, J. E., Guiltinan, M. J., Mieczkowski, P., Farmer, A., Ramaraj, T., Crozier, J., Davis, R. E., Shao, J., Melnick, R. L., Pereira, G. A., and Bailey, B. A. 2014. Genome and secretome analysis of the hemibiotrophic fungal pathogen, Moniliophthora roreri, which causes frosty pod rot disease of cacao: Mechanisms of the biotrophic and necrotrophic phases. BMC Genomics 15:164

Miller, S. M., and Magasanik, B. 1990. Role of NAD-linked glutamate dehydrogenase in nitrogen metabolism in Saccharomyces cerevisiae. J. Bacteriol. 172:4927-4935.

Miller, S. M., and Magasanik, B. 1991. Role of the complex upstream region of the GDH2 gene in nitrogen regulation of the NAD-linked glutamate dehydrogenase in Saccharomyces cerevisiae. Mol. Cell. Biol. 11:6229-6247.

Moy, M., Belanger, F., Duncan, R., Freehoff, A., Leary, C., Meyer, W., Sullivan, R., and White, J. F., Jr. 2000. Identification of epiphyllous mycelial nets on leaves of grasses infected by clavicipitaceous endophytes. Symbiosis 28:291-302.

O'Connell, R. J., Thon, M. R., Hacquard, S., Amyotte, S. G., Kleemann, J., Torres, M. F., Damm, U., Buiate, E. A., Epstein, L., Alkan, N., Altmuller, J., Alvarado-Balderrama, L., Bauser, C. A., Becker, C., Birren, B. W., Chen, Z., Choi, J., Crouch, J. A., Duvick, J. P., Farman, M. A., Gan, P., Heiman, D., Henrissat, B., Howard, R. J., Kabbage, M., Koch, C., Kracher, B., Kubo, Y., Law, A. D., Lebrun, M. H., Lee, Y. H., Miyara, I., Moore, N., Neumann, U., Nordstrom, K., Panaccione, D. G., Panstruga, R., Place, M., Proctor, R. H., Prusky, D., Rech, G., Reinhardt, R., Rollins, J. A., Rounsley, S., Schardl, C. L., Schwartz, D. C., Shenoy, N., Shirasu, K., Sikhakolli, U. R., Stuber, K., Sukno, S. A., Sweigard, J. A., Takano, Y., Takahara, H., Trail, F., van der Does, H. C., Voll, L. M. Will, I., Young, S., Zeng, Q., Zhang, J., Zhou, S., Dickman, M. B., Schulze-Lefert, P., Ver Loren van Themaat, E., Ma, L. J., and Vaillancourt, L. J. 2012. Lifestyle transitions in plant pathogenic Colletotrichum fungi deciphered by genome and transcriptome analyses. Nat. Genet. 44:1060-1067.

Oeser, B., Heidrich, P. M., Muller, U., Tudzynski, P., and Tenberge, K. B. 2002. Polygalacturonase is a pathogenicity factor in the Claviceps purpurea/rye interaction. Fungal Genet. Biol. 36:176-186.

Ozcan, S., Vallier, L. G., Flick, J. S., Carlson, M., and Johnston, M. 1997. Expression of the SUC2 gene of Saccharomyces cerevisiae is induced by low levels of glucose. Yeast 13:127-137.

Parniske, M. 2008. Arbuscular mycorrhiza: The mother of plant root endosymbioses. Nat. Rev. Microbiol. 6:763-775.

Plett, J. M., Kemppainen, M., Kale, S. D., Kohler, A., Legue, V., Brun, A., Tyler, B. M., Pardo, A. G., and Martin, F. 2011. A secreted effector protein of Laccaria bicolor is required for symbiosis development. Curr. Biol. 21:1197-1203.

Praekelt, U. M., and Meacock, P. A. 1992. MOL1, a Saccharomyces cerevisiae gene that is highly expressed in early stationary phase during 
growth on molasses. Yeast 8:699-710.

Praekelt, U. M., Byrne, K. L., and Meacock, P. A. 1994. Regulation of THI4 (MOL1), a thiamine-biosynthetic gene of Saccharomyces cerevisiae. Yeast 10:481-490.

Rasmussen, S., Lane, G. A., Mace, W., Parsons, A. J., Fraser, K., and Xue, H. 2012a. The use of genomics and metabolomics methods to quantify fungal endosymbionts and alkaloids in grasses. Methods Mol. Biol. 860:213-226.

Rasmussen, S., Liu, Q., Parsons, A. J., Xue, H., Sinclair, B., and Newman, J. A. 2012b. Grass-endophyte interactions: A note on the role of monosaccharide transport in the Neotyphodium lolii-Lolium perenne symbiosis. New Phytol. 196:7-12.

Regenberg, B., Holmberg, S., Olsen, L. D., and Kielland-Brandt, M. C. 1998. Dip5p mediates high-affinity and high-capacity transport of Lglutamate and L-aspartate in Saccharomyces cerevisiae. Curr. Genet. 33:171-177.

Rep, M. 2005. Small proteins of plant-pathogenic fungi secreted during host colonization. FEMS Microbiol. Lett. 253:19-27.

Rittenour, W. R., and Harris, S. D. 2013. Glycosylphosphatidylinositolanchored proteins in Fusarium graminearum: Inventory, variability, and virulence. PLoS One 8:e81603. Published online.

Robin, J. B., Arffa, R. C., Avni, I., and Rao, N. A. 1986. Rapid visualization of three common fungi using fluorescein-conjugated lectins. Invest. Ophthalmol. Visual Sci. 27:500-506.

Saikia, S., Takemoto, D., Tapper, B. A., Lane, G. A., Fraser, K., and Scott, B. 2012. Functional analysis of an indole-diterpene gene cluster for lolitrem B biosynthesis in the grass endosymbiont Epichloë festucae. FEBS (Fed. Eur. Biochem. Soc.) Lett. 586:2563-2569.

Schardl, C. L. 2001. Epichlö festucae and related mutualistic symbionts of grasses. Fungal Genet. Biol. 33:69-82.

Schardl, C. L., Leuchtmann, A., and Spiering, M. J. 2004. Symbioses of grasses with seedborne fungal endophytes. Annu. Rev. Plant Biol. 55:315-340

Schardl, C. L., Panaccione, D. G., and Tudzynski, P. 2006. Ergot alkaloids-biology and molecular biology. Pages 425-443 in: Alkaloids: Chemistry and Biology. G. A. Cordell, ed. Academic Press, San Diego, CA, U.S.A.

Schardl, C. L., Young, C. A., Hesse, U., Amyotte, S. G., Andreeva, K. Calie, P. J., Fleetwood, D. J., Haws, D. C., Moore, N., Oeser, B., Panaccione, D. G., Schweri, K. K., Voisey, C. R., Farman, M. L., Jaromczyk, J. W., Roe, B. A., O’Sullivan, D. M., Scott, B., Tudzynski, P., An, Z.-Q., Arnaoudova, E. G., Bullock, C. T., Charlton, N. D., Chen, L., Cox, M., Dinkins, R. D., Florea, S., Glenn, A. E., Gordon, A., Güldener, U., Harris, D. R., Hollin, W., Jaromczyk, J., Johnson, R. D., Khan, A. K., Leistner, E., Leuchtmann, A., Li, C., Liu, J.-G., Liu, J., Liu, M., Mace, W., Machado, C., Nagabhyru, P., Pan, J., Schmid, J., Sugawara, K., Steiner, U., Takach, J. E., Tanaka, E., Webb, J. S., Wilson, E. V., Wiseman, J. L., Yoshida, R., and Zheng, Z. 2013. Plant-symbiotic fungi as chemical engineers: Multi-genome analysis of the Clavicipitaceae reveals dynamics of alkaloid loci. PLoS Genet. 9:e1003323. Published online.

Schauer, N., Steinhauser, D., Strelkov, S., Schomburg, D., Allison, G., Moritz, T., Lundgren, K., Roessner-Tunali, U., Forbes, M. G., Willmitzer, L., Fernie, A. R., and Kopka, J. 2005. GC-MS libraries for the rapid identification of metabolites in complex biological samples. FEBS (Fed. Eur. Biochem. Soc.) Lett. 579:1332-1337.

Scott, B., Becker, Y., Becker, M., and Cartwright, G. 2012. Morphogenesis, growth and development of the grass symbiont Epichloë festucae. Pages 243-264 in: Morphogenesis and Pathogenicity in Fungi. J. P. Martin and A. Di Pietro, eds. Springer-Verlag, Heidelberg, Germany.

Skamnioti, P., and Gurr, S. J. 2007. Magnaporthe grisea cutinase2 mediates appressorium differentiation and host penetration and is required for full virulence. Plant Cell 19:2674-2689.

Solomon, P. S., Thomas, S. W., Spanu, P. D., and Oliver, R. P. 2003. The utilisation of di/tripeptides by Stagonospora nodorum is dispensable for wheat infection. Physiol. Mol. Plant Pathol. 63:191-199.

Spiering, M. J., Davies, E., Tapper, B. A., Schmid, J., and Lane, G. A. 2002. Simplified extraction of ergovaline and peramine for analysis of tissue distribution in endophyte-infected grass tillers. J. Agric. Food Chem. 50:5856-5862.

Storey, J. D., and Tibshirani, R. 2003. Statistical significance for genomewide studies. Proc. Natl. Acad. Sci. U. S. A. 100:9440-9445.
Tanaka, A., Tapper, B. A., Popay, A., Parker, E. J., and Scott, B. 2005. A symbiosis expressed non-ribosomal peptide synthetase from a mutualistic fungal endophyte of perennial ryegrass confers protection to the symbiotum from insect herbivory. Mol. Microbiol. 57:1036-1050.

Tanaka, A., Christensen, M. J., Takemoto, D., Park, P., and Scott, B. 2006. Reactive oxygen species play a role in regulating a fungus-perennial ryegrass mutualistic association. Plant Cell 18:1052-1066.

Tanaka, A., Cartwright, G. M., Saikia, S., Kayano, Y., Takemoto, D., Kato, M., Tsuge, T., and Scott, B. 2013. ProA, a transcriptional regulator of fungal fruiting body development, regulates leaf hyphal network development in the Epichloë festucae-Lolium perenne symbiosis. Mol. Microbiol. 90:551-568.

Tisserant, E., Kohler, A., Dozolme-Seddas, P., Balestrini, R., Benabdellah, K., Colard, A., Croll, D., Da Silva, C., Gomez, S. K., Koul, R., Ferrol, N., Fiorilli, V., Formey, D., Franken, P., Helber, N., Hijri, M. Lanfranco, L., Lindquist, E., Liu, Y., Malbreil, M., Morin, E., Poulain, J., Shapiro, H., van Tuinen, D., Waschke, A., Azcon-Aguilar, C., Becard, G., Bonfante, P., Harrison, M. J., Kuster, H., Lammers, P., Paszkowski, U., Requena, N., Rensing, S. A., Roux, C., Sanders, I. R., Shachar-Hill, Y., Tuskan, G., Young, J. P., Gianinazzi-Pearson, V., and Martin, F. 2012. The transcriptome of the arbuscular mycorrhizal fungus Glomus intraradices (DAOM 197198) reveals functional tradeoffs in an obligate symbiont. New Phytol. 193:755-769.

Valette-Collet, O., Cimerman, A., Reignault, P., Levis, C., and Boccara, M. 2003. Disruption of Botrytis cinerea pectin methylesterase gene Bcpme1 reduces virulence on several host plants. Mol. Plant-Microbe Interact. 16:360-367.

van den Ackerveken, G. F. J. M., Dunn, R. M., Cozijnsen, A. J., Vossen, J. P. M. J., van den Broek, H. W. J., and de Wit, P. J. G. M. 1994 Nitrogen limitation induces expression of the avirulence gene $a v r 9$ in the tomato pathogen Cladosporium fulvum. Mol. Gen. Genet. 243:277285.

van Esse, H. P., Bolton, M. D., Stergiopoulos, I., de Wit, P. J., and Thomma, B. P. 2007. The chitin-binding Cladosporium fulvum effector protein Avr4 is a virulence factor. Mol. Plant-Microbe Interact. 20:1092-1101

van Hove, L. W. A., Heeres, P., and Bossen, M. E. 2002. The annual variation in stomatal ammonia compensation point of rye grass (Lolium perenne L.) leaves in an intensively managed grassland. Atmosph. Environ. 36:2965-2977.

Vincent, D., Du Fall, L. A., Livk, A., Mathesius, U., Lipscombe, R. J., Oliver, R. P., Friesen, T. L., and Solomon, P. S. 2012. A functional genomics approach to dissect the mode of action of the Stagonospora nodorum effector protein SnToxA in wheat. Mol. Plant Pathol. 13:467-482.

Wang, C., and St Leger, R. J. 2007. The MAD1 adhesin of Metarhizium anisopliae links adhesion with blastospore production and virulence to insects, and the MAD2 adhesin enables attachment to plants. Eukaryot. Cell 6:808-816.

Wightman, R., and Meacock, P. A. 2003. The THI5 gene family of Saccharomyces cerevisiae: Distribution of homologues among the hemiascomycetes and functional redundancy in the aerobic biosynthesis of thiamin from pyridoxine. Microbiology 149:1447-1460.

Yoko-o, T., Matsui, Y., Yagisawa, H., Nojima, H., Uno, I., and Toh-e, A. 1993. The putative phosphoinositide-specific phospholipase C gene, PLC1, of the yeast Saccharomyces cerevisiae is important for cell growth. Proc. Natl. Acad. Sci. U. S. A. 90:1804-1808.

Young, C. A., Bryant, M. K., Christensen, M. J., Tapper, B. A., Bryan, G. T., and Scott, B. 2005. Molecular cloning and genetic analysis of a symbiosis-expressed gene cluster for lolitrem biosynthesis from a mutualistic endophyte of perennial ryegrass. Mol. Gen. Genomics 274:13-29.

Young, C. A., Felitti, S., Shields, K., Spangenberg, G., Johnson, R. D., Bryan, G. T., Saikia, S., and Scott, B. 2006. A complex gene cluster for indole-diterpene biosynthesis in the grass endophyte Neotyphodium lolii. Fungal Genet. Biol. 43:679-693.

Zhao, Z., Liu, H., Wang, C., and Xu, J. R. 2014. Correction: Comparative analysis of fungal genomes reveals different plant cell wall degrading capacity in fungi. BMC Genomics 15:6.

\section{AUTHOR-RECOMMENDED INTERNET RESOURCE}

National Institute of Standards and Technology 08: www.nist.gov 